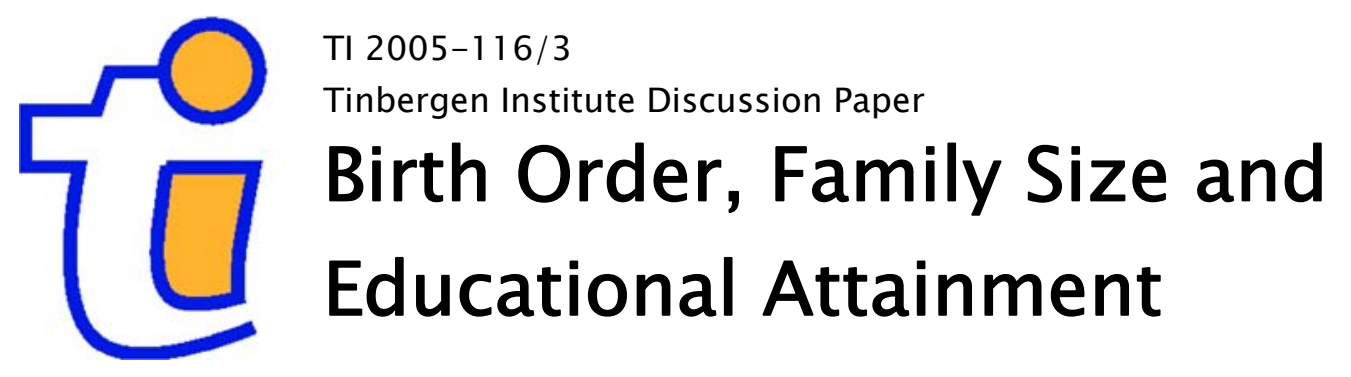

Monique de Haan

University of Amsterdam, and Tinbergen Institute. 


\section{Tinbergen Institute}

The Tinbergen Institute is the institute for economic research of the Erasmus Universiteit Rotterdam, Universiteit van Amsterdam, and Vrije Universiteit Amsterdam.

Tinbergen Institute Amsterdam

Roetersstraat 31

1018 WB Amsterdam

The Netherlands

Tel.: $\quad+31(0) 205513500$

Fax: $\quad+31(0) 205513555$

Tinbergen Institute Rotterdam

Burg. Oudlaan 50

3062 PA Rotterdam

The Netherlands

Tel.: $\quad+31(0) 104088900$

Fax: $\quad+31(0) 104089031$

Please send questions and/or remarks of nonscientific nature to driessen@tinbergen.nl.

Most TI discussion papers can be downloaded at http://www.tinbergen.nl. 


\title{
Birth Order, Family Size and
}

\section{Educational Attainment}

\author{
Monique de Haan*
}

\begin{abstract}
This paper investigates the effect of sibship size and birth order on educational attainment, for the United States and the Netherlands. An instrumental variables approach is used to identify the effect of sibship size. Instruments for the number of children are twins at last birth and the sex mix of the first two children. The effect of birth order is identified, by examining the relation with years of education for different family sizes separately; this avoids the problem that estimated effects confound birth order with family size. No significant effect of the number of children on educational attainment of the oldest child is found. Birth order has a significant negative effect. This negative effect does not differ between children from higher or lower educated parents. Also the age gap between children does not affect the effect of birth order, or the educational attainments of the children. These last two results suggest that competition between siblings for scarce parental time and resources is not an important cause of the birth order effects.
\end{abstract}

\section{Introduction}

Many studies indicate that birth order and family size are important determinants of educational outcomes of children. Family size and birth order are strongly related, although family size differs between children from different families, while birth order differs between children within a family. In previous research often no clear distinction between sibship size and birth

\footnotetext{
${ }^{*}$ Contact information: Monique de Haan, "Scholar", Department of Economics, University of Amsterdam, Roetersstraat 11, 1018 WB Amsterdam, The Netherlands, email: M.deHaan1@uva.nl. Thanks go to Erik Plug, Hessel Oosterbeek, Bas van der Klaauw, Edwin Leuven, Adam Booij and Chris van Klaveren for their help and useful comments. This research uses data from the Wisconsin Longitudinal Study (WLS) of the University of Wisconsin-Madison. Since 1991, the WLS has been supported principally by the National Institute on Aging (AG-9775 and AG-21079), with additional support from the Vilas Estate Trust, the National Science Foundation, the Spencer Foundation, and the Graduate School of the University of Wisconsin-Madison. A public use file of data from the Wisconsin Longitudinal Study is available from the Wisconsin Longitudinal Study, University of Wisconsin-Madison, 1180 Observatory Drive, Madison, Wisconsin 53706 and at http://www.ssc.wisc.edu/ $\sim$ wls/data/. The opinions expressed herein are those of the author.
} 
order is made and estimated effects of sibship size could be picking up the effect of birth order and visa versa. Because of the strong relation between birth order and family size this paper estimates the effects of both family background components on years of education, for the United States and for the Netherlands.

The relationship between family size and subsequent educational attainment can be the result of constraints on parental resources. When there are capital market imperfections and parents have many children, they can, for a given income, invest less in each child than if they have fewer children. This can cause a negative relationship between family size and educational attainment (Becker (1981)). Also numerous empirical studies have found a negative relationship between the number of siblings, and future economic and educational achievements (Blake (1981), Hanushek (1992)).

The negative relationship between sibship size and educational achievements typically found in literature is however not necessarily proof of a negative effect of the number of children. The number of children is a choice variable of the parents and it might be that certain characteristics of parents, such as their educational attainments, affect both the number of children as well as the educational attainments of those children. This can cause a negative correlation between the number of siblings and future educational achievement, even if no causal effect of the number of siblings exists. Consequently a simple ordinary least squares regression of educational attainment on the number of children in a family will likely give biased and inconsistent results.

This paper uses an instrumental variable (IV) approach to identify the effect of sibship size on years of education of a first-born child. Two sources of exogenous variation in the number of children are used; twins at last birth, and the preference of parents for a mixed sibling sex composition. Recent studies have also used twins or the sex mix of children as instruments to identify the effect of the number of children; Angrist and Evans (1998) to identify the effect on parents' labour supply, Black, Devereux and Salvanes (2005), Angrist, Lavy and Schlosser (2005) and Dalton and Glauber (2005) to estimate the effect on educational achievements of children. No study has however identified the effect of sibship size on years of education for the United States or for the Netherlands. Also because the literature using instruments to identify the effect of family size is still relatively sparse, it is certainly important to apply this methodology to different data sets, from various countries.

Like many studies, this paper finds a negative correlation between the number of children 
and educational attainment, and this is especially true for the United States. This negative correlation declines however when control variables like parental education and birth order dummies are added. This signals that the observed negative correlation might not be causal. The IV results indeed are no longer significantly negative, but positive and insignificant. Although the standard errors are not small, these results indicate that exogenous variation in the number of children does not have a significant negative effect on the educational attainment of a child.

Birth order is also believed to have an effect on the human capital of an individual. Models from psychology, Zajonc (1976), predict a decline in intellectual environment with birth order, which can cause a negative effect of birth order on educational achievements. Economist emphasize the constraints on available parental time and resources, which can cause a negative effect of birth order on educational outcomes (Becker(1981), Behrman (1997)). Later born children have to share the available time and resources with their siblings for a larger part of their childhood, than earlier born children. Some empirical studies have indeed found a negative effect (Behrman and Taubman(1986), Black, Devereux and Salvanes (2005), but others have found no systematic effect of birth order on educational attainment (Blake(1981), Hauser and Sewel (1985)).

This paper identifies the effect of birth order by estimating the effect on years of education separately for families with two, three, four or five children. Family size is correlated with birth order, and not taking this into account would give estimates of the birth order effects which might confound birth order with family size, or with family characteristics which are correlated with family size. Estimating the effect of birth order separately for families with a different number of children avoids this problem. For all family sizes examined in this paper, birth order turns out to have a significant negative effect on educational attainment, for both the United States and the Netherlands. This decline in years of education with birth order turns out to be approximately linear.

Although some other studies have also investigated the effect of birth order, hardly any study has investigated what is behind the estimated birth order effects. To investigate if restrictions on parental time and resources are behind the birth order effects, an interaction term of birth order with parental education is included in the analysis. Higher educated parents have on average more resources and the restrictions will be less severe, which is expected to decrease 
the negative effect of birth order. Also competition between siblings for scarce parental time is expected to be more severe if the age gap between children is smaller. Therefore the effect of the time between births is investigated, taking into account the possible endogeneity of the space between births, by using the presence of twins as instrument.

The results show that both for the Netherlands and for the United States, the negative effect of birth order does not differ significantly between children with higher or lower educated parents. Also the average number of months between subsequent births has no significant effect on the educational attainment of a child. Nor does the average space between births affect the negative effect of birth order on educational attainment. Although the data provide no information on actual time and resources spent by the parents on each child, these results indicate that competition between closely spaced siblings for scarce parental time and resources does not seem to be an important cause of the negative effect of birth order.

The plan of the paper is as follows. Section 2 will give an overview of the theoretical and empirical literature. Section 3 continues with a description of the data used, section 4 gives the empirical specification and sections 5 and 6 give the results for respectively the effect of family size and birth order on years of education. Finally section 7 concludes.

\section{Theoretical and empirical background}

\subsection{Family size and educational attainment}

There is an extensive theoretical literature about the trade-off between child quality and quantity, dating back to the models of Becker and Lewis (1973) and Becker and Tomes (1976). The idea behind these theoretical models is that if parents have more children, investing a certain amount in per-child quality, for example their education, is more expensive, than if they have fewer children. If parents decide to have $n$ children, investing an amount $x$ in child quality gives a total cost of investment in child quality of $n \cdot x$. When there is an (exogenous) increase in the number of children $n$, the total cost of investing a certain amount in per-child quality becomes higher and for a given budget constraint parents will lower the investment in per-child quality. This indicates that there is a negative relation between child quantity and child quality.

However, parents not only have an influence on child quality through investment of resources, but also through transmission of their endowments. The endowment of a child depends on many separate factors; the endowment of his father, the endowment of his mother and the 
environment in which he is raised. If parents with lower endowments have a higher preference for child quantity than parents with higher endowments, and therefore also have more children, this can cause a negative correlation between child quantity and child quality, by way of the effect of parental endowments on child quality. Children of parents with low endowments will in this case have on average more siblings and a lower educational attainment, even though there may be no causal effect of the number of children on educational attainment.

Most of the empirical literature investigating the relation between child quantity and quality perform a least squares regression of economic and educational outcomes on sibship size and other socioeconomic background variables. Most of these studies have found a significant negative relation between the number of children and the educational achievements of those children. Belmont and Marolla (1973) use a sample of around 400,000 19-year-old males born in the Netherlands between 1944 and 1947. They find a negative relation between family size and intellectual performance, measured as the score on a military examination (Raven Progressive Matrices). This negative relation is however not consistent for all social classes examined, where the social classes were based on father's occupation. Blake (1981) uses different survey data sets from the United States, and finds that the number of siblings correlates negatively with educational attainment. Hanushek (1992) estimates the effect of the number of children on achievements in school, whereby achievements are defined as test scores from the Iowa Reading Comprehension and Vocabulary tests. The main finding in this paper is that family size has a significant negative relation with school achievements of children, and he concludes that a distinct trade-off between the quantity and quality of children is found to exist.

These studies do however not take the possible endogeneity of the number children into account. Recently the effect of family size on educational achievement is investigated using an instrumental variable approach. Black, Devereux and Salvanes (2005) use multiple births as instruments for the number of children, to investigate the effect of sibship size on children's education in Norway. They find a negative correlation between family size and educational attainment, but when they include control variables such as birth order dummies, and when they use the twin births as instruments, they find no significant negative effect of the number of children on educational attainment. They look only at Norwegian data and their results might not generalize to other countries. The study in this paper applies a similar methodology by using twins as instrument to identify the effect of family size using data from the United States 
and the Netherlands. It further complements their paper by using the sex mix of the first two children as instrument for family size, next to the twins instrument ${ }^{1}$. By using both instruments the effect of family size can be identified using different sources of exogenous variation.

Dalton and Glauber (2005) use the sex mix of the first two children as instrument for family size. They use the 1990 five percent Public Use Micro Data Samples (PUMS) to estimate the effect of sibship size on children's private school attendance, and on their likelihood of being held back in school. The authors find small but significant negative effects of the number of siblings. They find that this causal relationship is moderated by birth order. They do however not investigate the effect of the number of siblings on the final educational attainment of an individual, and only look at children who are younger than 20 and who still reside with their parents. Looking only at children co-residing with their parents is a disadvantage, because the number of children reported in the census need not be equal to the total number of children of the householders. This is not a problem in the study in this paper, because for the data from the United States as well as from the Netherlands all children are reported in the survey, whether they are still residing with their parents or not, also completed education is known for the majority of the children in both samples.

Angrist, Lavy and Schlosser (2005) use exogenous variation in family size both due to twin births and due to the preference for a mixed sibling sex composition. They also include interactions of these instruments with ethnicity, exploiting the difference in the effects of the instruments between Jews from European or North American origin and Jews of Asian or North African origin. Using Israeli Census data matched to information from the population registry, they find negative and significant OLS coefficients, but using the instruments they find no significant effect of the number of children on educational and labor market outcomes. The study by Angrist, Lavy and Schlosser uses twins at second or at third birth as instrument for the number of children. Families who had twins at nth birth and who have more than $n+1$ children in total would however likely have had more than $n+1$ children anyway, even if they would not have had twins at nth birth. The investigation in this paper uses instead twins at last birth and this prevents using multiple births as exogenous variation in the number of children, while the parents wanted more children anyway.

\footnotetext{
${ }^{1}$ Black, Devereux and Salvanes (2005) briefly mention some results using the sex mix of the first two children as instrument. They find a significant postive effect of the number of children on years of education, and they do not find the magnitude of their estimate credible.
} 


\subsection{Birth order and educational attainment}

Different theories predict a significant effect of birth order on future educational and economic achievements. An important model in the psychological literature is the confluence model, which is discussed by Zajonc (1976). The confluence model predicts the intellectual growth of a child to depend on its intellectual environment, whereby the intellectual environment is defined as a function of the average of the absolute intellectual levels of its family members. A first child enters an environment with two adult parents, so the average intellectual level is high. A second born enters a lower intellectual environment than the first born, because his older sibling is part of the intellectual environment, and decreases the average intellectual level. A third child enters an even lower intellectual environment than the second born because of two older siblings, who decrease the average intellectual level in the family etcetera. This model therefore predicts a negative correlation between birth order and educational attainment, because the intellectual environment declines with birth order. Zajonc however stresses the effect of child spacing, the larger the age gap between two siblings the smaller is the difference between the two children in their intellectual environment, and the smaller is the effect of birth order.

Economic theories underline the restrictions on available time and resources of the parents (Becker(1981), Behrman (1997)). The time spent by parents on their children is seen as an important input into the human capital of those children. Later born children probably spend on average less time with their parents than earlier born children. A first born does not have to share his parent's time with siblings until a second child is born. The second child has to share his mother's and father's time with its older sibling, but only from the moment a third child is born, he or she has to share with another sibling. So in particular if time spent in the early childhood is more important than time spent with children when they are older, later born children are disadvantaged compared to earlier born children, because parents cannot spend as much time with later born children, as they did with earlier born children.

Not only restrictions on the amount of available time can cause a negative effect of birth order on educational attainment, but also limitations on the amount of resources available to invest in the human capital of the children may cause a negative effect. If parents simultaneously decide on the number of children and the quality of those children, that is how much to invest in each of their children, no birth order effect would be expected, unless parents explicitly favor earlier born children over later born children. In the quantity-quality model it is implicitly 
assumed that parents take the cost of investment in their children into account when deciding on the number of children. However if parents are not enough forward looking, or when it is difficult for parents to estimate the actual amount of resources necessary to invest in their children's education, later born children may find that most resources have been depleted by older siblings, at the moment they need resources to finance their education. Also unexpected births may cause this effect.

A binding budget constraint can, however, also favor later born children over earlier born children, especially when the age difference between a child and his earlier born siblings is quite large. If the age gap is large, later born children do not have to compete so much with earlier born children, and if parents have an upward sloping earnings profile and there are capital market imperfections, parents can even have more resources available to invest in later born children, than they had available for their earlier born children.

Empirical studies have found different effects of birth order. Belmont and Marolla (1973) examine, next to the effect of family size, the effect of birth order for given family sizes. They find a steady decline in average Raven scores with birth order, and in contrast to the effect of family size, the effect of birth order is present for all social classes examined. Blake (1981) also examines the effect of birth order and does not find a systematic difference in educational attainment between first and last borns, and middle born children. Hauser and Sewel (1985) use the sample of 9000 Wisconsin high school graduates of 1957 and their siblings. In this sample also no significant or systematic effects of birth order on educational attainment are found. A drawback of this sample is that all graduates have at least high school. Later in this paper the offspring of these graduates will be examined, and the variation in years of education is larger among the children in this sample, there are both children with more than a high school degree as children with less than a high school degree.

Behrman and Taubman (1986) study the birth order effect for the adult offspring of the twins in the National Academy of Science/National Research Council (NAS/NRC) sample. They find in contrast to the previous two studies, significant positive effects of being an early born on (age-adjusted) schooling, and for some specifications they also find positive effects of a low birth order on the logarithm of earnings. Behrman and Taubman include the number of children next to other family background characteristics in their specification, because the estimates of the birth order effects might confound birth order with family size. This does however not solve the 
problem entirely, it is still difficult to separate the effect of birth order and family size, because of the high correlation between birth order and the number of children, and the number of children is likely endogenous. The study in this paper investigates the effect of birth order for families with two, three, four and five children separately. In this way estimated effects of birth order cannot confound with the effect of family size.

Black, Devereux and Salvanes (2005) use data from Norway. Next to the investigation of the effect of the number of children on years of education, they also examine the effect of birth order for different family sizes separately. By including birth order dummies they find a significant negative effect of birth order on educational attainment, for all family sizes examined. Later in this paper a similar method will be used to investigate the effect of birth order on years of education for children from the Netherlands and the United States. In addition some of the mechanisms which could be behind the estimated birth order effects are investigated.

\section{Data}

\subsection{Wisconsin Longitudinal Study (WLS)}

One of the data sets used in the empirical study in this paper comes from the Wisconsin Longitudinal Study, which is a long-term study of a random sample of 10,317 men and women who graduated from Wisconsin high schools in 1957. Survey data were collected from the original respondent or their parents in 1957, 1964, 1975, and 1992, and from a selected sibling in 1977 and 1994. All respondents were born around 1939/1940.

Wisconsin is a state in the central north of the United States. It is one of the leading states in agriculture; almost one-half of the land area of the state is covered by farmland, but the number of farms has declined over the second half of the 20th century. Around two thirds of the population is Christian and most of these people are Roman Catholic. Children in Wisconsin start compulsory schooling at age 6 and have to attend school until age 18 or when they graduate from high school.

In 1957 the data collection started with a questionnaire to the random sample of graduates. The questions were related to the students' social background (for example parent's education and occupation and numbers of older and younger siblings), intelligence (measured as a standardized IQ test score), and aspirations. Subsequently, research was continued on a randomly selected one third of the original cohort. 
In 1964 the parents of the graduates were mailed a postcard questionnaire, in order to update the social and economic situation of the graduates. In 1975, the original respondents were contacted by telephone and were asked questions about social background, occupation, education, marriage, children, and social activities. In 1992 the same sample of persons was contacted once more, in order to collect new information about detailed occupational histories and job characteristics; incomes, assets, inter-household transfers, social and economic characteristics of parents, siblings, and children and descriptions of the respondents' relationships with them.

For the study in this paper the data set is reduced to include only intact families, with a minimum of two and a maximum of five children. Intact means that the respondent and his or her partner lived together during the youth of their children and have never divorced. This selection of the data set is necessary to be sure that siblings lived together during their childhood. When parents get divorced it happens that some children live with their mother and the other children live with their father, and in these kind of circumstances the number of children reported in the survey is not equal to the number of children that lived with the respondent during the childhood of the children. Including only intact families reduces the number of respondents from 10,317 to $5,481^{2}$, and eliminating all respondents with less than two children and more than five children reduces the data set to 4704 respondents.

Families with more than five children are excluded, because in the birth order analysis families of different sizes are examined separately, and for families with more than five children this is not possible due to sample size problems. The sample is further restricted to families with only biological children, because it might be the case that adopted children are treated differently by their adoptive parents than biological children. Moreover the effect of birth order is examined in this paper, and adopted children who become part of a family some years after they were born might complicate the analysis. This restriction reduces the sample to 12,985 children from 4,343 families. Table 1 gives descriptive statistics of the sample.

The sample contains children who have not finished their reported years of education, or who are still in school, so some adjustments had to be made to the education variable. The

\footnotetext{
${ }^{2}$ All regressions in this paper also have been performed without this selection of the data set and the results were very similar to those reported in the paper. To avoid complications in interpreting the results, for example when children did not live together during their childhood because their parents did not live together, only results for the selected sample are presented.
} 
education variable reports years of attended schooling and for those children who are older than 27, and who did not finish their final year of education, one year is subtracted from the reported years of schooling. Children who were younger than 27 in 1993 and for whom was reported that they went to school in the past 12 months, are treated as censored observations. Including them in the sample without taking account of the fact that they hadn't finished their education in 1993, or simply excluding them would give biased and inconsistent results.

\subsection{Brabant survey}

The second data set used in the empirical study in this paper comes from the Brabant survey, which also is a long-term study of a random sample of men and women, who were in the 8th grade in 1952 in the province of Noord-Brabant in the Netherlands. The Brabant survey studies a similar birth cohort as the Wisconsin Longitudinal Study; the children in the 8th grade in 1952 were also born around 1939/1940. Just like Wisconsin, agriculture is important for the province of Noord-Brabant, around two third of the province is covered by farmland. Also Roman Catholicism is the most important religion in this province. Children in NoordBrabant attend compulsory school from age five to age sixteen, and after age sixteen children have to attend school only for some part of the week. Also the structure of the data set is very similar to the Wisconsin Longitudinal Study; the Brabant survey started in 1952 with a questionnaire under pupils and their parents, and when the pupils were adults they were contacted again to get more information about labour market status, partner and children.

The prime motivation for the survey in 1952 was to investigate the situation in primary education and to use this information so as to improve the level of education in the province of Noord-Brabant. Information from this survey were related to the pupils' social background (for example parent's education and occupation and numbers of older and younger siblings), intelligence tests and performance in school.

In 1983 the individuals were contacted again to obtain information about educational attainment, school performance, social background, occupation and (wage) income. A questionnaire was send to all individuals for whom a valid address was found and $58 \%$ of the original sample responded to this questionnaire. This follow-up survey was implemented to obtain data for empirical labour market analyses.

In 1993, the same sample of persons was contacted once more, in order to collect new information about detailed occupational histories, job characteristics and income, also information 
was collected about the partner and children of the respondent. The questionnaire contained questions about the number of children, their birth order and their educational attainment. The highest level of education a child ever attended was reported in seven categories, and a question about whether the child finished this grade and whether he or she was still in school was also included in the questionnaire. The information about educational attainment reported in categories is translated to years of schooling for the analysis in this paper. For respondents, partners and children who did not finish their reported educational level, it is assumed that they dropped out and they are assigned the years of education midway of the years assigned to the reported level, and those assigned to the next lower level. In the empirical analysis of the next sections the children below 27, who were still in school in 1993 are treated as censored observations as was discussed for the data from the Wisconsin Longitudinal Study (WLS).

Although the Brabant survey and the Wisconsin Longitudinal Study are very similar in structure, the Brabant survey does not contain detailed information about whether children are biological or adopted, and whether there are children present from previous marriages, so most of the selections made for the Wisconsin Longitudinal Study are not possible for the Brabant survey. The final Brabant sample consists of respondents who were living together with their partner at the time of the last questionnaire, this reduces the sample from 3,167 to 1,846 respondents ${ }^{3}$. Further only respondents who have a minimum of two and a maximum of five children are included in the sample. This final restriction reduces the sample to 3090 children from 1,246 families. The descriptive statistics are presented in table $1^{4}$.

\section{Empirical model}

Both data sets used in the next sections contain children who have not finished their education, and not taking this into account would give biased and inconsistent results. If children who are still in school were just included in the samples, this would be a problem especially for the analysis of the effect of birth order. Children with a high birth order are also the youngest chil-

\footnotetext{
${ }^{3}$ Just as for the WLS data (see footnote 2) all regressions in this paper have also been performed without this selection of the data set and the results were again very similar to those reported in the paper.

${ }^{4}$ The years of education for the child and especially the father and the mother are lower compared to the WLS data. This is due to the fact that the Brabant survey contains respondents with less than high school, whereas the WLS data set only includes respondents with at least a high school diploma. Looking only at respondents in the Brabant survey who have at least high school increases the average years of schooling of the child to 14.03, and the average years of schooling of the father and the mother increase to 13.74 and 11.64 respectively.
} 
dren in the sample, and they are most likely the children who have not finished their education. This would give a negative correlation between birth order and educational attainment, even if birth order has no causal effect on educational attainment. Excluding children who have not finished their education would also bias the results because in this case mostly children from higher educated parents will be excluded. Parents in both samples do not differ much in age and parents with higher education often have children at a later age, so the youngest children in the sample are more likely from higher educated parents. For this reason the next sections will use a censored regression model, whereby the education of a child is a latent variable which is completely observed for part of the observations, but incompletely observed for the other part of the observations.

$$
\begin{aligned}
& E_{\text {child }}^{*}=E_{\text {child }} \text { if a child is no longer in school }\left(d_{i}=0\right) \\
& E_{\text {child }}^{*} \geq E_{\text {child }} \text { if a child is still in school }\left(d_{i}=1\right)
\end{aligned}
$$

$E_{\text {child }}^{*}$ is the final level of educational attainment and $E_{\text {child }}$ is the observed level of education. The disturbances are assumed to be normally distributed and the censored maximum likelihood maximizes

$$
\ln L(\theta)=\sum_{i=1}^{N}\left[\left(1-d_{i}\right) \cdot \ln \phi\left(E_{\text {child }, i} \mid x_{i}, \theta\right)+d_{i} \cdot \ln \left\{1-\Phi\left(E_{\text {child }, i} \mid x_{i}, \theta\right)\right\}\right]
$$

whereby $\phi$ is the normal density, $\Phi$ is the normal distribution function, $\theta$ are the parameters of the distribution and $x_{i}$ are the explanatory variables which are specified in the next sections.

Section 5 will investigate the effect of the number of siblings on years of education, and section 6 will examine the effect of birth order.

\section{$5 \quad$ Family size and educational attainment}

\subsection{Censored regression results}

In previous studies the relation between the number of children and the educational attainment of a child is usually estimated using an ordinary least squares specification. In this section the possible endogeneity of the number of children will also initially be ignored, and a censored regression model will be estimated. The following equation will be estimated three times, each 
time with a different set of control variables.

$$
E_{\text {child }}=\alpha \cdot \text { numberofchild }+X \cdot \beta+\varepsilon
$$

First $X$ only contains the age and gender of the child, then the years of education of the father and the mother are included, and finally a set of dummies indicating whether the child is a second, third, fourth or fifth born are added to the specification. The highest level of attained schooling, measured in years of education, is used as dependent variable and the variable numberof child ranges from two to five children. Table 2 shows the estimation results of this equation for the United States and for the Netherlands.

As can be seen in the first column of table 2, the censored regression coefficient on the number of children is significantly negative for the United States. The magnitude of the coefficient declines however when paternal and maternal education are added as control variables. This signals that the number of children is endogenous, and that the school choice of parents is somehow related to their decision about the number of children. Another possibility is that the negative effect of family size is picking up the negative effect of birth order. Therefore in column 3 birth order dummies are added, and indeed the coefficient on the number of children declines even further and is no longer significant. The birth order dummies are however all significantly negative.

A similar pattern is observed for the Dutch data set. The coefficient on the number of children in column 4 is negative but not significant, and when father's and mother's education are added the coefficient is cut in half, just as in the WLS data set. When birth order dummies are added the censored regression coefficient even turns positive and is marginally significant at the $10 \%$ level. The birth order dummies are however all significantly negative, again indicating that the effect of family size in columns 4 and 5 might be picking up the effect of birth order. It is however not possible to conclude from these tables what the causal effect of the number of children is. It is also difficult to separate the effect of birth order and sibship size in columns 3 and 6 , because the number of children and the birth order dummies are strongly correlated ${ }^{5}$.

The results in table 2 do show that certain family background characteristics, such as parental education might be associated with the number of children, as well as with the level

\footnotetext{
${ }^{5}$ The correlation between a continuous variable birth order and the number of children is equal to 0.45 for the WLS data and equal to 0.47 for the Brabant survey. The continuous birth order variable has the value zero for a first born child, the value one for a second born child etc. The variable ranges from zero to four.
} 
of education of a child. The exogeneity assumption on the variable numberof child is therefore likely violated, making the censored regression estimator biased and inconsistent. The next subsection uses exogenous variation in the number of children to identify the effect of sibship size on years of education.

\subsection{Instrumental variables results}

To identify the effect of the number of children on the educational attainment of the first-born child, twins at last birth and the sex mix of the first two children will be used as instruments ${ }^{6}$.

Twins at last birth is a variable, which takes on the value one in three situations; when there are three children in the family and the second birth is a twin, when there are four children and the third birth is a twin and the final situation is when there are five children and the fourth birth is a twin. Other papers using twins as exogenous variation (Black, Devereux and Salvanes (2005), Angrist, Lavy and Schlosser (2005)) use twins at second, third or higher birth as instrument for the number of children. A drawback of this method is that a family, who had for example twins at second birth and who have four children in total, would very likely also have had four children when the second birth would have been a single birth instead. Looking only at the last birth in a family prevents using a twin birth as exogenous variation in family size, while the parents wanted more children anyway.

For twins at last birth to be a valid instrument for the number of children, it should have no separate effect on the educational attainment of the first born child. If child-spacing has an effect on educational attainment, this could be a potential problem, because in the case of twins the space is zero. If the age gap between two children is smaller the competition between siblings for time and parental funds is likely higher, which can have a negative effect on the education of a child, separate from the effect via the number of children. Estimating for fixed family sizes the effects of the number of months between two subsequent births, gives coefficients which are all not significantly different from zero ${ }^{7}$. This indicates that the space

\footnotetext{
${ }^{6}$ See Rosenzweig and Wolpin (2000) for a discussion on the use of these instruments.

${ }^{7}$ The following equations are estimated for families with three (eq1), four (eq2) and five children (eq3). $E_{\text {oldestchild }}=\alpha+\delta_{1} \cdot$ space $23+X \cdot \beta+\varepsilon, E_{\text {oldestchild }}=\alpha+\delta_{1} \cdot$ space $23+\delta_{2} \cdot$ space $34+X \cdot \beta+\varepsilon, E_{\text {oldestchild }}=$ $\alpha+\delta_{1} \cdot$ space $23+\delta_{2} \cdot$ space $34+\delta_{3} \cdot$ space $45+X \cdot \beta+\varepsilon$, whereby $X$ contains age and gender of the oldest child. Results for the WLS sample are for three child families: $\widehat{\delta_{1}}=0.002(0.003)$, four child families: $\widehat{\delta_{1}}=0.004(0.005)$, $\widehat{\delta_{2}}=0.003(0.003)$, and for five child families: $\widehat{\delta_{1}}=0.002(0.012), \widehat{\delta_{2}}=-0.007(0.008), \widehat{\delta_{3}}=-0.006(0.005)$. And for the Brabant survey the results are as follows. Three child families: $\widehat{\delta_{1}}=-0.051(0.070)$, four child families: $\widehat{\delta_{1}}=0.318$ (0.168), $\widehat{\delta_{2}}=-0.036$ ( 0.086), and five child families: $\widehat{\delta_{1}}=-0.280(0.371), \widehat{\delta_{2}}=0.255(0.228), \widehat{\delta_{3}}=0.146(0.236)$.
} 
between births has no significant effect on educational attainment. In subsection 6.3 the effect of child-spacing will be investigated more thoroughly. Further the probability of having twins at last birth might be affected by certain characteristics of parents, such as their educational attainment. Results from linear probability models show however that the education of both the father and the mother have no significant effect on the probability of having twins at last birth, for both data $\operatorname{sets}^{8}$. These results indicate that the instrument twins at last birth has no separate effect on the educational attainment of the first-born child, although this remains of course an untestable assumption.

The sex mix of the first two children will also be used as an instrument. If the first two children are of the same sex, parents are significantly more likely to have another child, because of the widely observed preference of parents for a mixed sibling sex composition (Ben-Porath and Welch (1976), Angrist and Evans (1998)) $)^{9}$. For the samesex instrument to be valid, it should also have no effect on the educational attainment of a child, separate from the effect via the number of children. Some papers indicate that the number of brothers and sisters can have an effect on educational outcomes. Butcher and Case (1994) find that, while controlling for family size, women raised with only brothers have a significantly higher educational attainment than women with any sisters. Hauser and Kuo (1998) report however that no effect of the sibling sex composition on educational attainment for the sample of 9000 Wisconsin high school graduates has been found. They go on to perform a similar analysis as Butcher and Case on three survey data sets, and they do not find any evidence for an effect of the gender composition of sibships on years of completed schooling. Also Kaestner (1997) does not find significant effects of sibling sex composition on the educational attainment of white males and females.

For both data sets used in this paper, two dummy variables are added to the specification in equation (2), one for having only sisters and one for having only brothers, children with both brothers and sisters are the control group. This specification is estimated for the oldest children, separately for boys and for girls. Both dummy variables have an insignificant effect on the educational attainment of the oldest child, both for boys and for girls, for the Dutch

\footnotetext{
${ }^{8}$ For the WLS data the coefficient on father's education is equal to $-0.0008(0.0007)$ and the coefficient on mother's education is equal to 0.0015 (0.0010). For the Brabant survey they are equal to -0.0001 (.0011) for father's education and -0.0015 (0.0014) for mother's education.

${ }^{9}$ Angrist and Evans also use the sex mix of the first two children as an instrument for the number of children, to test the effect of childbearing on labour supply.
} 
data set as well as for the data from the United States ${ }^{10}$. These results indicate that the gender composition of sibships does not have a significant effect on educational attainment. So in the subsequent analysis it is assumed that the samesex instrument has no effect on the education of the oldest child, separate from the effect via the number of children.

First twins at last birth will be used as an instrument. Only the effect of the number of children on the education of the oldest child is examined, because children who are born as second, third, fourth or fifth and who are part of a twin can be affected directly by the instrument. Children who are part of a twin have, for example, often a lower birth weight than children not part of a multiple birth and this might affect their later educational attainment (Black, Devereux and Salvanes $(2005 b)^{11}$.

The following model will be estimated

$$
\begin{aligned}
& E_{\text {child }, i}^{*}=\alpha_{0}+\alpha_{1} \cdot \text { numberof child } d_{i}+X_{i} \cdot \beta+v_{i} \\
& \text { numberofchild }_{i}=\delta_{0}+\delta_{1} \cdot Z_{i}+X_{i} \cdot \psi+\eta_{i}
\end{aligned}
$$

Whereby $Z_{i}$ is the instrumental variable for the number of children, and $E_{c h i l d}^{*}$ is the final number of years of education, which is only observed for part of the observations. The remaining observations are treated as censored. $X$ contains age and gender of the oldest child and years of education of both the father and the mother. In the appendix the log likelihood function of the model in equations (3) and (4) is derived.

For the WLS data information is included on whether a birth is a twin, but for the Brabant survey only information on year of birth is available. For the Brabant survey the dummy $Z$ has the value one when the last two children have the same year of birth, so some children assigned to be twins might actually not be twins, but just born in the same year, although this is not very likely.

\footnotetext{
${ }^{10}$ For the first born children from the WLS data set the following results are found. For boys the coefficient on 'only sisters' is equal to $-0.043(0.161)$ and the coefficient on 'only brothers' is equal to 0.091 (0.156). For girls the coefficients are equal to 0.191 (0.151) for 'only sisters' and $0.160(0.151)$ for 'only brothers'. And for the first born children from the Brabant survey the results are as follows. For boys the coefficient on 'only sisters' is equal to $-0.436(0.394)$ and the coefficient on 'only brothers' is equal to $0.0776(0.381)$. For girls the coefficients are equal to 0.591 (0.391) for 'only sisters' and 0.344 (0.394) for 'only brothers'.

${ }^{11}$ Black, Devereux and Salvanes (2005) find using within twin techniques with data from Norway, that birth weight has a significant effect on educational attainment.
} 
Next the instrument samesex will be used. The model specification is the same as in equations (3) and (4), except that $Z$ is now a dummy variable, which takes on the value one, when the first two children are of the same sex.

Table 3 shows the coefficients on the instrument $Z$ in equation (4) for the United states and the Netherlands. For the WLS data, both instruments have a significant effect on the number of children. The partial F-statistic on the instrument twins at last birth is equal to 31.70, and equal to 23.72 for the instrument samesex. An instrument should have a sufficiently strong effect on the endogenous explanatory variable and an often used rule of thumb is that the partial F-statistic should be larger than 10, which is the case for both instruments here ${ }^{12}$. Also for the Dutch data set twins at last birth has a significant effect on the number of children with a partial F-statistic equal to 45.02. The instrument samesex has however no significant effect on the number of children and the second stage result is therefore likely biased, and does not give credible information about the effect of the number of children.

Table 4 shows the censored regression results for the first-born child, without taking into account the endogeneity of the variable numberofchild and it shows the censored regression results whereby twins at last birth, respectively samesex is used as an instrument ${ }^{13}$. The censored regression coefficient on the number of children in row (1) is negative but not significant for the WLS data set, and positive and insignificant for the Brabant survey. The second stage estimation results in rows (2) and (3) show that for the United States, the effect of the number of children on years of education of the oldest child is positive, but not significant. This shows that the censored regression estimator of the effect of the number of children is negatively biased, because both second stage results give a positive coefficient on the number of children,

\footnotetext{
${ }^{12}$ Staiger and Stock (1997) investigate the finite sample bias of the IV estimator relative to the bias of the OLS estimator. They find that in a simple model the inverse of the F-statistic is an approximate estimate of the relative bias of the IV estimator. If the F-statistic is larger than 10, this gives a finite sample bias of the instrumental variable estimator of no more than $10 \%$ of the OLS bias.

${ }^{13}$ Parents with three boys or three girls are also more likely to have a fourth child compared to parents with three children with a mixed sex composition, as is shown for example in Ben-Porath and Welch (1976). The sex mix of the first three children could therefore be a possible instrument for the number of children in a sample of families with at least three children. The first stage using the sex mix of the first three children as an instrument is however relatively weak for the WLS sample with a partial F-statistic equal to 6.55, and the effect of sex mix on the number of children in the Brabant survey is not even significantly different from zero (partial F-statistic is 1.08). Results using the sex mix of the first three children as an instrument are therefore not shown in tables 4 and 5. The effect (standard error) of the number of children on the years of education of the oldest child using the sex mix of the first three children as an instrument is equal to 0.660 (1.298), for the WLS data whereby only families with at least three children are included. For the Brabant survey the effect (standard error) of the number of children is equal to -3.784 (6.453).
} 
irrespective of whether twins at last birth or the sex mix of the first two children is used as instrument $^{14}$. The second stage results for the Netherlands in row (2), when twins at last birth is used as instrument, again show a positive but insignificant effect of the number of children on the educational attainment of the oldest child ${ }^{15}$. Although the standard errors are not small these results for the United States and the Netherlands show that the number of children has in fact no significant negative effect on educational attainment. The second stage results are positive and insignificant for both countries and this is similar to findings by recent studies using exogenous variation in the number of children (Black, Devereux and Salvanes (2005) and Angrist, Lavy and Schlosser (2005)).

\section{Birth order and educational attainment}

\subsection{Censored regression results}

To identify the effect of birth order on years of education, the effect of birth order is estimated for different family sizes separately. For a given family size, estimated effects of birth order cannot confound with the effect of the number of children, which is an endogenous variable. Equation (14) will be estimated separately for families with two, three, four and five children.

$$
E_{\text {child }}^{*}=\beta \cdot \text { Birthorder }_{\text {child }}+X \cdot \phi+\eta
$$

Birthorder child is a set of dummies, indicating whether the child is a second, third, fourth or fifth born, and $X$ includes age and gender of the child. Table 5 gives the results of the censored regression model, for the United States and the Netherlands.

For the WLS data the birth order dummies are all significantly negative, for all family sizes considered, and the higher the birth order the more negative the effect is. The results for the Brabant survey are very similar. The decline in years of education with birth order is approximately linear. This becomes even more clear in figures 1 and 2, where for each family size the predicted educational attainments, based on the results in table 5 , are plotted against birth order. Another notable element in figures 1 and 2 is that for a given birth order, the

\footnotetext{
${ }^{14}$ Due to the large standard errors it is however not possible to reject the hypothesis that the censored-IV coefficients are equal to the censored regression coefficient.

${ }^{15} \mathrm{Also}$ here it is not possible to reject the hypothesis that the censored regression and censored-IV coefficients are equal, due to the large standard errors.
} 
difference between children with a large number of siblings and children with a smaller number of siblings is very small. There is, for example, no large systematic difference between a third born child from a three child family and a third born child from a four or five child family, whereas for a given family size there is a large difference between children with a different birth order. These results are consistent with the findings in the previous section.

Because birth order has an effect which is almost linear, the effect of birth order could as

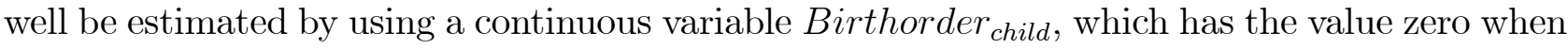
an individual is a first born, the value one when he or she is a second born etc. This gives a variable which ranges from zero to four. Results using this continuous variable instead of the birth order dummies are shown in table 6.

Birth order has a relatively large negative effect on the schooling of an individual. The coefficient is between 0.45 and 0.78 for all family sizes considered, for both the United States as for the Netherlands. A second child has, for example, on average around 0.60 years of education less than a first born child, and a third child has on average 1.30 years of education less than an oldest child etcetera. Also the birth order effects for families with two, three, four and five child families are not significantly different from one other ${ }^{16}$.

One possible reason for the negative effects is that the intellectual environment declines with birth order, like Zajonc predicts in his confluence model. Another possibility is that limitations on the available amount of parental time and resources have a stronger negative effect on later born children, because earlier born children do not have to compete with so many siblings, especially in their early childhood. The next two subsections will investigate whether constraints on parental resources and competition between closely spaced siblings are important causes of the negative effect of birth order.

\subsection{Birth order and parental education}

If constraints on parental resources are to some extent responsible for the effect of birth order, the negative effect of birth order will likely be smaller for children from higher educated parents. Higher educated parents have on average more resources than lower educated parents, and the constraints will be less severe. To investigate whether the negative effect of higher birth order declines with father's education, the following equation will be estimated, again for fixed family

\footnotetext{
${ }^{16}$ The $\chi^{2}$-statistic (p-value) of the test of equality of the birth order coefficients in table 6 is equal to 1.31 (0.727) for the WLS data and equal to 0.84 (0.841) for the Brabant survey.
} 
sizes as in subsection 6.1.

$$
\begin{gathered}
E_{\text {child }}=\theta_{0}+\theta_{1} \cdot E_{\text {father }}+\theta_{2} \cdot \text { Birthorder }_{\text {child }}+ \\
\theta_{3} \cdot\left(E_{\text {father }} \cdot \text { Birthorder }_{\text {child }}\right)+X \cdot \beta+\varepsilon
\end{gathered}
$$

In subsection 6.1 it was shown that birth order has approximately a linear effect, and therefore the continuous variable Birthorder child $_{\text {is }}$ used here. If the effect of birth order is indeed less negative for children from higher educated parents, the coefficient on the interaction term $\left(\theta_{3}\right)$ will be positive. The estimation results of equation (6) are shown in table 7.

For both the WLS data, as for the data from the Brabant survey, none of the interaction terms with father's education are significantly different from zero, except for the coefficient for four child families, which is marginally significant. If constraints on the available resources are an important cause of the negative effect of birth order, the interactions are expected to be positive and significant, but although most coefficients on the interaction terms are positive none of them is significant at a $5 \%$ significance level ${ }^{17}$. Figures 3 and 4 also show that the pattern of the birth order effects does not differ between children with fathers with at most high school (at most 12 years of education) and children from fathers with more than high school (more than 12 years of education). In these figures for each family size the predicted educational attainments are plotted against birth order in the same way as was done in figures 1 and 2, except that in figures 3 and 4 a difference is made between children from higher and lower educated fathers. Both the results in table 7 and in figures 3 and 4 show that constraints on the available amount of parental resources do not seem to be a major determinant of the negative effect of birth order.

\subsection{The effect of child spacing}

The average time between births is expected to have a positive effect on educational attainment. When the age gap between children is small the childhoods of the children overlap for a large part. The total number of years that parents can spend on their children before they become adults will therefore be smaller, than when the time between births is larger. Suppose that children benefit from parental time until they become 21. If parents have two children and the

\footnotetext{
${ }^{17}$ Except for the coefficient for four child families from the Brabant survey.
} 
time between the first and second birth is one year, the number of years from the moment the first child is born until the moment that the second child becomes 21 , is 22 years. So these parents have 22 years to spend on one or both of their children. If instead the time between the first and second child is five years, parents have 27 years to spend on one or both of their children. So constraints on the total amount of time parents can spend on their children are less severe when the time between births is larger.

Also the negative effect of birth order is expected to be smaller when the time between births is larger. Father's and mother's time is considered to be most important in the first couple of years after a child is born. Later born children have to share this time with more siblings than earlier born children did, and they will therefore likely receive less parental time in their early childhood, compared their older siblings. This difference between earlier and later born children is expected to be even larger when the average space between births is smaller. The need for parental time likely declines when children get older, because they become better able to take care of themselves. When the age gap between a later born child and his older siblings is small, the older siblings will need a lot of parental time in the first years after the birth of the later born child, because they will still be in their early childhood. If instead the age gap is larger, more time will be available in the early childhood of this later born child, because his older siblings are older and need less parental time.

The confluence model from psychology also predicts a decline in the birth order effect with the average space between births. The intellectual environment that later born children enter, will not differ much from the intellectual environment that earlier born children entered, when the age gap between earlier born and later born children is sufficiently large. When earlier born children are already almost adults when a child is born, this child does not suffer much from his higher birth order, in terms of a lower intellectual environment.

To test the effect of the average number of months between subsequent births, the following two equations will be estimated.

$$
\begin{gathered}
\mathrm{E}_{\text {child }}=\alpha_{0}+\alpha_{1} \cdot \text { Birthorder }_{\text {child }}+\alpha_{2} \cdot \text { averagespace }+X \cdot \beta+\varepsilon \\
\mathrm{E}_{\text {child }}=\delta_{0}+\delta_{1} \cdot \text { Birthorder }_{\text {child }}+\delta_{2} \cdot \text { averagespace }+ \\
\delta_{3} \cdot\left(\text { averagespace } \cdot \text { Birthorder }_{\text {child }}\right)+X \cdot \gamma+\eta
\end{gathered}
$$


The first equation includes the variable averagespace, which is the average number of months between subsequent births in a family of two, three, four or five children. For a four child family, for example, this variable is constructed by adding the number of months between the first two children, the number of months between the second and the third child and the number of months between the last two children, and dividing this number by three. For the Brabant survey only the number of years between two children is known, and to get a similar measure as for the WLS data, the average number of years between subsequent births is multiplied by 12. Further the continuous variable Birthorder child is included as well as years of education of the father and mother, and age and gender of the child. If competition between closely spaced siblings for available parental time has a negative effect on their educational attainment, the coefficient on the variable averagespace will likely be positive. Also the confluence model predicts a positive coefficient.

The second equation includes as an extra variable the interaction of birth order and the average number of months between births, so as to investigate how spacing affects the negative effect of birth order. If the negative effect of birth order is indeed smaller when the time between subsequent births is larger, the coefficient on the interaction term $\left(\delta_{3}\right)$ will be positive. Table 8 shows the estimation results of the two equations, for the United States and the Netherlands.

The average number of months between two children does not have a significant effect ${ }^{18}$ on the educational attainment of a child, as can be seen in the first part of table 8. Also the interaction terms of birth order and the average space are insignificant, both for the United States and for the Netherlands. This holds for all family sizes considered, except for four child families in the United States, where the interaction term is significant but negative instead of the expected positive sign. These results indicate that competition between closely spaced siblings does not seem to be an important cause of the negative effect of birth order.

The time between subsequent births can however be chosen by the parents. If certain characteristics of parents have an effect on the average space between births, as well as on the education of the children, the average number of months between births is endogenous. To identify the effect of the average time between births on educational attainment, the presence of twins among the children in a family is used as an instrument. If a twin is born the space

\footnotetext{
${ }^{18}$ At a $5 \%$ significance level.
} 
between two births is zero, which is an exogenous decrease in the average time between births. The following model will be estimated

$$
\begin{gathered}
\mathrm{E}_{\text {child }, i}^{*}=\alpha_{0}+\alpha_{1} \cdot \text { averagespace }_{i}+X_{i} \cdot \beta+v_{i} \\
\text { averagespace }_{i}=\delta_{0}+\delta_{1} \cdot Z_{i}+X_{i} \cdot \phi+\eta_{i}
\end{gathered}
$$

Where $Z_{i}$ is the instrumental variable which takes on the value one when either the first, second, third or fourth birth is a twin ${ }^{19} 20$.

A twin birth also has a significant effect on the number of children as was shown in section 5.2. The model above will however be estimated separately for families with two, three, four and five children, so this does not impose a problem here. Part A of table 9 shows the effect of the presence of twins on the average number of months between births, as well as the partial F-statistics. The presence of twins has a significant negative effect on the average number of months between births. For the WLS sample the partial F-statistics are larger than 10 for all family sizes considered, and this also holds for two and three child families in the Brabant survey.

Part A of table 10 gives the censored regression results whereby the presence of twins is used as an instrument for the variable averagespace ${ }^{21}$. The results show that the average space between births has no significant effect on years of education of a child. Instead of the expected positive effect, the IV coefficients are for most family sizes negative and for all family sizes insignificant. These IV results also indicate that competition between closely spaced siblings for scarce parental time does not seem to have an important effect on the education of a child. Wald tests cannot reject the null hypothesis of exogeneity of the variable averagespace ${ }^{22}$.

\footnotetext{
${ }^{19}$ There are no families with more than one twin in the WLS sample or in the Brabant survey.

${ }^{20} \mathrm{It}$ is assumed that $v_{i}$ and $\eta_{i}$ are multivariate normally distributed, and following the same reasoning as in the appendix this gives the following log likelihood:

$$
\begin{aligned}
& \ln L(\theta)=\sum_{i=1}^{N}\left[\left(1-d_{i}\right) \cdot \ln \phi\left(E_{\text {child }, i} \mid \text { averagespace }_{i}, X_{i}, Z_{i}, \theta\right)+\right. \\
&\left.d_{i} \cdot \ln \left\{1-\Phi\left(E_{\text {child }, i} \mid \text { averagespace }_{i}, X_{i}, Z_{i}, \theta\right)\right\}+\ln \phi\left(\text { averagespace }_{i} \mid X_{i}, Z_{i}, \theta\right)\right]
\end{aligned}
$$

${ }^{21}$ For five child families in the Brabant survey the number of observations is very small (117 children from 24 families) and there are only 3 families with a twin. As a consequence the maximum likelihood estimation did not converge and therefore no results are presented in tables 9 and 10 for five child families from the Brabant survey.

${ }^{22}$ The $\chi^{2}$-statistics are for the WLS-data for respectively two, three, four and five child family's equal to
} 
The presence of twins could however have a separate effect on years of education. If the education of a child is affected by being part of a $\operatorname{twin}^{23}$, the instrument could have a direct effect on years of education. For children from families with at least three children it is possible to estimate the model above excluding the children who are part of a twin. The first stage results whereby children part of a twin are excluded are shown in part B of table 9 . Part B of table 10 shows the second stage results for the sample without children part of a twin. None of the coefficients in part B of table 10 are significantly different from the results in part A, except for three child families in the WLS sample where the coefficient on the average space between births is significantly negative ${ }^{24}$. If competition between closely spaced siblings has a negative effect on their educational attainment, the coefficient on the variable averagespace is expected to be positive. Although for three child families in the WLS sample the coefficient is significantly different from zero, it's sign is negative. This also indicates that competition between closely spaced siblings for scarce parental time does not seem to have a significant negative effect on their later educational attainment ${ }^{25}$.

\section{Conclusion}

Many theoretical and empirical studies indicate that between-family differences and withinfamily differences have a significant effect on educational achievements. This paper has investigated the causal effect of the number of siblings and birth order on years of education, for the Netherlands and the United States.

By using twins at last birth and the sex mix of the first two children as instruments, the effect of the number of children on the educational attainment of the oldest child is identified.

0.10, 1.82, 1.96 and 0.41. For the Brabant survey they are respectively for two, three and four child family's equal to $0.04,0.20$ and 0.32 .

${ }^{23}$ As was already mentioned in previous sections, children part of a twin have on average a lower birth weight compared to singletons and this might affect there later educational attainment.

${ }^{24}$ The $\chi^{2}$-statistic (p-value) of the test of equality of the coeffients on the variable averagespace in part A of table 10 and in part B are equal to 4.35 (0.037) for three child families, 0.45 (0.503) for four child families and equal to 0.09 (0.759) for five child families in the United States. For the Brabant survey the $\chi^{2}-$ statistic (p-value) is equal to 2.52 ( 0.112$)$ for three child families and equal to 0.38 (0.535) for four child families. Again for five child families in the Brabant survey the maximum likelihood estimation does not converge because the number of observations is too small.

${ }^{25} \mathrm{~A}$ negative effect of the average space between births on the educational attainment of a child could be explained by children benefiting from interacting with their siblings. If siblings do not differ much in age they might interact more with each other for example by making home work together and this could have a positive effect on their later educational achievements. 
Although for both countries the censored regression estimate of the effect of the number of children on the educational attainment of a child is negative, the IV results show a positive and insignificant effect of the number of children on years of education of the oldest child. This indicates that the negative correlation between sibship size and educational attainment found in this paper, and found in other papers (Belmont and Marolla (1973), Blake (1981), Hanushek (1992)), might actually be caused by unobserved family characteristics, which affect the number of children as well as the educational achievements of those children.

The effect of birth order is identified by investigating the effect of birth order for two, three, four and five child families separately. For a fixed family size birth order is random, and estimated effects cannot confound with the effect of the number of children, or with the (unobserved) family characteristics which are highly correlated with the number of children. Birth order turns out to have a significant negative effect on years of education, for both data sets used in this paper, for all family sizes examined. This is in contrast to the findings by Blake (1981) and Hauser and Sewel (1985) but the results are very similar to those found by Behrman and Taubman (1986) and Black, Devereux and Salvanes (2005).

There are different theories which predict a negative effect of birth order. To examine whether restrictions on available parental time and resources are the key determinant of the negative birth order effect, an interaction term of father's education with birth order is included in the analysis. Higher educated parents have on average more resources, so if constraints on resources cause the negative effect of birth order, the interaction terms are likely positive. The results of this paper show however, that the effect of birth order does not differ significantly for children from higher, or lower educated parents. Also the average number of months between subsequent births does not have a significant effect on the educational attainment of a child, or on the effect of birth order. If the average space between siblings is larger the constraints on parental time are smaller, which likely has a positive effect on the educational attainment of a child. So these results show that constraints on parental resources and competition between closely spaced siblings for scarce parental time do not seem to be responsible for the negative effect of birth order.

The data sets used in this paper provide however no exact information about time and resources that are spent by the parents on their children, also other explanations for the effect of birth order need to be examined, so clearly more research is necessary to investigate what is 
behind the effects found in this paper.

\section{References}

[1] Angrist, J.D., Evans, W.N.(1998). Children and Their Parents' Labor Supply: Evidence from Exogenous Variation in Family Size. The American Economic Review, Vol 88, (3), 450-477.

[2] Angrist, J.D., Lavy, V. and Schlosser, A.(2005). New Evidence on the Causal Link between the Quantity and Quality of Children, mimeo, Hebrew University Department of Economics.

[3] Becker, B.S. (1981). A Treatise on the Family. Cambridge: Harvard University Press.

[4] Becker, B.S., and Lewis, H.G. (1973). On the Interaction between the Quantity and Quality of Children. Journal of Political Economy, Vol 81 (2), S279-S288.

[5] Becker, B.S., and Tomes, N (1976). Child Endowments and the Quantity and Quality of Children. Journal of Political Economy, Vol 84 (4), S143-S162.

[6] Behrman, J. (1997). Intrahousehold Distribution and the Family. In Rosenzweig M. R., Stark, O. (eds) Handbook of Population Economics, volume I. Amsterdam: Elsevier Science.

[7] Behrman, J.R., and Taubman, P. (1986). Birth Order, Schooling and Earnings. Journal of Labor Economics, Vol 4 (3), 121-145.

[8] Belmont, L., and Marolla, F. A. (1973). Birth Order, Family Size, and Intelligence. Science, Vol 182 (4117), 1096-1101.

[9] Ben-Porath, Y., and Welch, F.(1976). Do Sex Preferences Really Matter? The Quarterly Journal of Economics, Vol 90 (2), 285-307.

[10] Black, S.E., Devereux, P.J., and Salvanes, K.G. (2005). The More the Merrier? The Effect of Family Size and Birth Order on Children's Education. The Quarterly Journal of Economics, Vol 120 (2), 669-700.

[11] Black, S.E., Devereux, P.J., and Salvanes, K.G. (2005b). From the Cradle to the Grave? The Effect of Birth Weight on Adult Outcomes of Children, mimeo.

[12] Blake, J. (1981). Family Size and the Quality of Children. Demography, Vol 18, (4), 421-442

[13] Bound, J., Jaeger, D.A., Baker, R.M. (1995). Problems with Instrumental Variables Estimation When the Correlation Between the Instruments and the Endogenous Explanatory 
Variable is Weak. Journal of the American Statistical Association,Vol 90,(430), 443-450.

[14] Butcher, K.F, Case, A. (1994). The Effect of Sibling Sex Composition on Women's Education and Earnings. The Quarterly Journal of Economics, Vol 109, 531-563.

[15] Dalton, C., Glauber, R.(2005). Parental Educational Investment and Children's Academic Risk: Estimates of the Impact of Sibship Size and Birth Order from Exogenous Variation in Fertility. National Bureau of Economic Research (NBER), working paper 11302.

[16] Hanushek, E.A. (1992). The trade of between Child Quantity and Quality. The Journal of Political Economy, Vol 100, 84-117.

[17] Hauser, R.M., and Kuo, H.D. (1998). Does the Gender Composition of Sibships Affect Women's Educational Attainment? The Journal of Human Resources, Vol 33, (3), 644657.

[18] Hauser, R.M., and Sewel, W.H. (1985). Birth Order and Educational Attainment in Full Sibships. American Educational Research Journal, Vol 22 (1), 1-23.

[19] Kaestner, R. (1997). Are Brothers Really Better: Sibling Sex Composition and Educational Achievement Revisited. Journal of Human Resources, Vol 32 (2), 250-284.

[20] Rosenzweig, M.R., and Wolpin, K.I. (2000). Natural "Natural Experiments" in Economics. Journal of Economic Literature. Vol 38, (4), 827-874.

[21] Staiger, D., and Stock, J.H. (1997). Instrumental Variables Regression with Weak Instruments. Econometrica, Vol 65 (3), 557-586.

[22] Wisconsin Longitudinal Study (WLS) [graduates]: 1992/93. [machine-readable data file] / Hauser, Robert M.; Sewell, William H.; Hauser, Taissa S. [principal investigator(s)]. Madison, WI: University of Wisconsin-Madison, WLS. [distributor]; $<$ http://www.ssc.wisc.edu/ wls/documentation/>

[23] Zajonc, R.B. (1976). Family Configuration and Intelligence. Science, Vol 192, 227-236. 
Table 1: Descriptive statistics

\begin{tabular}{l|cc|cc}
\hline \hline & WLS & Data & Brabant & Survey \\
\hline & Mean & Standard deviation & Mean & Standard deviation \\
\hline Years of education child & 13.91 & 2.46 & 13.36 & 2.95 \\
Years of education mother & 12.91 & 1.73 & 10.13 & 2.74 \\
Years of education father & 13.52 & 2.64 & 11.46 & 3.54 \\
Age child & 26.38 & 4.62 & 24.57 & 4.02 \\
Gender child & 0.49 & 0.50 & 0.47 & 0.50 \\
Twins at last birth & 0.012 & 0.109 & 0.019 & 0.138 \\
Samesex & 0.52 & 0.50 & 0.49 & 0.50 \\
Average number of months between births & 32.70 & 14.69 & 33.76 & 17.11 \\
Twin present in family & 0.029 & 0.167 & 0.033 & 0.180 \\
Number of children & 3.35 & 0.97 & 2.76 & 0.82 \\
\hline \hline Number of families & 4343 & & 1246 & 3090 \\
Number of children & 12985 & & \\
\hline \hline
\end{tabular}


Table 2. The effect of the number of children on years of education

\begin{tabular}{|c|c|c|c|c|c|c|}
\hline & \multicolumn{3}{|c|}{ WLS data } & \multicolumn{3}{|c|}{ Brabant survey } \\
\hline & $\begin{array}{l}\text { Censored } \\
\text { regression } \\
\text { (1) }\end{array}$ & $\begin{array}{l}\text { Including } \\
\text { parental } \\
\text { education } \\
\text { (2) }\end{array}$ & $\begin{array}{c}\text { Including } \\
\text { parental education } \\
\& \text { birth } \\
\text { order dummies } \\
\text { (3) }\end{array}$ & $\begin{array}{l}\text { Censored } \\
\text { regression } \\
\text { (4) }\end{array}$ & $\begin{array}{l}\text { Including } \\
\text { parental } \\
\text { education } \\
\text { (5) }\end{array}$ & $\begin{array}{c}\text { Including } \\
\text { parental education } \\
\& \text { birth } \\
\text { order dummies } \\
\text { (6) }\end{array}$ \\
\hline Number of children & $\begin{array}{l}-0.298^{* * *} \\
(0.033)\end{array}$ & $\begin{array}{l}-0.155^{* * *} \\
(0.027)\end{array}$ & $\begin{array}{l}-0.038 \\
(0.030)\end{array}$ & $\begin{array}{l}-0.083 \\
(0.118)\end{array}$ & $\begin{array}{l}-0.043 \\
(0.106)\end{array}$ & $\begin{array}{l}0.187^{*} \\
(0.113)\end{array}$ \\
\hline $\begin{array}{l}\text { Years of } \\
\text { education father }\end{array}$ & & $\begin{array}{l}0.295^{* * *} \\
(0.012)\end{array}$ & $\begin{array}{l}0.285^{* * *} \\
(0.012)\end{array}$ & & $\begin{array}{l}0.239 * * * \\
(0.025)\end{array}$ & $\begin{array}{l}0.233^{* * *} \\
(0.025)\end{array}$ \\
\hline $\begin{array}{l}\text { Years of } \\
\text { education mother } \\
\text { Birthorder: }\end{array}$ & & $\begin{array}{l}0.294^{* * *} \\
(0.019)\end{array}$ & $\begin{array}{l}0.283^{* * *} \\
(0.019)\end{array}$ & & $\begin{array}{l}0.205^{* * *} \\
(0.033)\end{array}$ & $\begin{array}{l}0.194^{* * *} \\
(0.033)\end{array}$ \\
\hline Second & & & $\begin{array}{l}-0.361^{* * *} \\
(0.047)\end{array}$ & & & $\begin{array}{l}-0.293^{* *} \\
(0.126)\end{array}$ \\
\hline Third & & & $\begin{array}{l}-0.555^{* * *} \\
(0.068)\end{array}$ & & & $\begin{array}{l}-0.711^{* * *} \\
(0.222)\end{array}$ \\
\hline Fourth & & & $\begin{array}{l}-0.846^{* * *} \\
(0.102)\end{array}$ & & & $\begin{array}{l}-1.550^{* * *} \\
(0.408)\end{array}$ \\
\hline Fifth & & & $\begin{array}{l}-0.915^{* * *} \\
(0.168)\end{array}$ & & & $\begin{array}{l}-2.512^{* * *} \\
(0.723)\end{array}$ \\
\hline Censored observations & 3200 & 3200 & 3200 & 784 & 784 & 784 \\
\hline Number of observations & 12985 & 12985 & 12985 & 3090 & 3090 & 3090 \\
\hline
\end{tabular}

All regressions include control variables for gender and age of the child. Standard errors (in parentheses) allow for correlation within families. *significant at $10 \%$ level, ${ }^{*}$ significant at $5 \%$ level, ${ }^{* * *}$ significant at $1 \%$ level

Table 3: First stage; the effect of twins at last birth respectively samesex on the number of children

\begin{tabular}{l|cl|cc}
\hline \hline & \multicolumn{2}{|c|}{ WLS data } & \multicolumn{2}{c}{ Brabant survey } \\
\hline \multirow{2}{*}{ Effect on number of children } & $0.779^{* * *}$ & $0.132^{* * *}$ & $1.182^{* * *}$ & 0.041 \\
& $(0.138)$ & $(0.027)$ & $(0.176)$ & $(0.041)$ \\
& 31.70 & 23.72 & 45.02 & 0.98 \\
Partial F-statistic & 496 & 496 & 148 & 148 \\
Censored observations & 4232 & 4232 & 1212 & 1212 \\
Number of observations & & & Twins at last birth & samesex \\
\hline \hline
\end{tabular}

All regressions include control variables for gender and age of the first born child, father's years of education and mother's years of education. Standard errors are in parentheses. *significant at $10 \%$ level, **significant at $5 \%$ level, ***significant at $1 \%$ level 
Table 4: Censored \& censored-IV results of the effect of numberofchild on education of the oldest child

\begin{tabular}{l|c|c|c}
\hline \hline & & WLS data & Brabant survey \\
\hline Effect on years of education & & & \\
\hline Censored regression & $(1)$ & -0.046 & 0.094 \\
& & $(0.039)$ & $(0.119)$ \\
Censored-IV using twins at last birth as instrument: & $(2)$ & 0.349 & 0.322 \\
& & $(0.458)$ & $(0.644)$ \\
Censored-IV using samesex as instrument: & $(3)$ & 0.525 & 8.786 \\
& & $(0.540)$ & $(9.759)$ \\
Number of censored observations & $(4)$ & 496 & 148 \\
Number of observations & $(5)$ & 4232 & 1212 \\
\hline \hline
\end{tabular}

All regressions include control variables for gender and age of the first born child, father's years of education and mother's years of education. Standard errors are in parentheses.

*significant at $10 \%$ level, ${ }^{* *}$ significant at $5 \%$ level, $* * *$ significant at $1 \%$ level

Table 5. The effect of birth order on years of education, for fixed family sizes

\begin{tabular}{|c|c|c|c|c|c|c|c|c|}
\hline & \multicolumn{4}{|c|}{ WLS data } & \multicolumn{4}{|c|}{ Brabant survey } \\
\hline & $\begin{array}{c}\text { Two child } \\
\text { family }\end{array}$ & $\begin{array}{c}\text { Three child } \\
\text { family }\end{array}$ & $\begin{array}{l}\text { Four child } \\
\text { family }\end{array}$ & $\begin{array}{l}\text { Five child } \\
\text { family }\end{array}$ & $\begin{array}{l}\text { Two child } \\
\text { family }\end{array}$ & $\begin{array}{c}\text { Three child } \\
\text { family }\end{array}$ & $\begin{array}{c}\text { Four child } \\
\text { family }\end{array}$ & $\begin{array}{c}\text { Five child } \\
\text { family }\end{array}$ \\
\hline Second & $\begin{array}{l}-0.564^{* * *} \\
(0.096)\end{array}$ & $\begin{array}{l}-0.619^{* * *} \\
(0.078)\end{array}$ & $\begin{array}{l}-0.572^{* * *} \\
(0.093)\end{array}$ & $\begin{array}{l}-0.592^{* * *} \\
(0.150)\end{array}$ & $\begin{array}{l}-0.583^{* * *} \\
(0.177)\end{array}$ & $\begin{array}{l}-0.792^{* * *} \\
(0.176)\end{array}$ & $\begin{array}{c}0.101 \\
(0.318)\end{array}$ & $\begin{array}{l}-0.794 \\
(0.559)\end{array}$ \\
\hline Third & & $\begin{array}{l}-1.110^{* * *} \\
(0.114)\end{array}$ & $\begin{array}{l}-1.042^{* * *} \\
(0.124)\end{array}$ & $\begin{array}{l}-0.901^{* * *} \\
(0.186)\end{array}$ & & $\begin{array}{l}-1.553^{* * *} \\
(0.288)\end{array}$ & $\begin{array}{l}-0.854^{*} \\
(0.459)\end{array}$ & $\begin{array}{l}-0.904 \\
(0.775)\end{array}$ \\
\hline Fourth & & & $\begin{array}{l}-1.637^{* * *} \\
(0.184)\end{array}$ & $\begin{array}{l}-1.532^{* * *} \\
(0.230)\end{array}$ & & & $\begin{array}{c}-1.891^{\text {*** }} \\
(0.659)\end{array}$ & $\begin{array}{l}-2.473^{* *} \\
(0.111)\end{array}$ \\
\hline Fifth & & & & $\begin{array}{l}-1.79^{* * *} \\
(0.317)\end{array}$ & & & & $\begin{array}{l}-2.866^{*} \\
(0.491)\end{array}$ \\
\hline $\begin{array}{l}\text { Censored } \\
\text { observations }\end{array}$ & 841 & 1146 & 812 & 407 & 380 & 337 & 112 & 33 \\
\hline $\begin{array}{l}\text { Number of } \\
\text { observations }\end{array}$ & 2801 & 4669 & 3746 & 1817 & 1568 & 1367 & 479 & 140 \\
\hline
\end{tabular}

All regressions include control variables for gender and age of the child. Standard errors (in parentheses)

allow for correlation within families. ${ }^{*}$ significant at $10 \%$ level, ${ }^{* *}$ significant at $5 \%$ level, $* * *$ significant at $1 \%$ level 
Table 6. The effect of birth order (continuous variable) on years of education, for fixed family sizes

\begin{tabular}{|c|c|c|c|c|c|c|c|c|}
\hline & \multicolumn{4}{|c|}{ WLS data } & \multicolumn{4}{|c|}{ Brabant survey } \\
\hline & $\begin{array}{c}\text { Two child } \\
\text { family }\end{array}$ & $\begin{array}{c}\text { Three child } \\
\text { family }\end{array}$ & $\begin{array}{c}\text { Four child } \\
\text { family }\end{array}$ & $\begin{array}{c}\text { Five child } \\
\text { family }\end{array}$ & $\begin{array}{c}\text { Two child } \\
\text { family }\end{array}$ & $\begin{array}{c}\text { Three child } \\
\text { family }\end{array}$ & $\begin{array}{c}\text { Four child } \\
\text { family }\end{array}$ & $\begin{array}{c}\text { Five child } \\
\text { family }\end{array}$ \\
\hline Birth order & $\begin{array}{c}-0.564^{* * *} \\
(0.096)\end{array}$ & $\begin{array}{c}-0.559^{* * *} \\
(0.056)\end{array}$ & $\begin{array}{c}-0.537^{* * *} \\
(0.058)\end{array}$ & $\begin{array}{c}-0.459^{* * *} \\
(0.074)\end{array}$ & $\begin{array}{c}-0.583^{* * *} \\
(0.177)\end{array}$ & $\begin{array}{c}-0.777^{* * *} \\
(0.142)\end{array}$ & $\begin{array}{c}-0.632^{* * *} \\
(0.213)\end{array}$ & $\begin{array}{l}-0.737^{* *} \\
(0.377)\end{array}$ \\
\hline $\begin{array}{l}\text { Censored } \\
\text { observations }\end{array}$ & 841 & 1146 & 812 & 407 & 380 & 337 & 112 & 33 \\
\hline $\begin{array}{l}\text { Number of } \\
\text { observations }\end{array}$ & 2801 & 4669 & 3746 & 1817 & 1568 & 1367 & 479 & 140 \\
\hline
\end{tabular}

All regressions include control variables for gender and age of the child. Standard errors (in parentheses) allow

for correlation within families. ${ }^{*}$ significant at $10 \%$ level, ${ }^{* *}$ significant at $5 \%$ level, ${ }^{* * *}$ significant at $1 \%$ level

Table 7. Effect of interaction term father's education with birth order on years of education

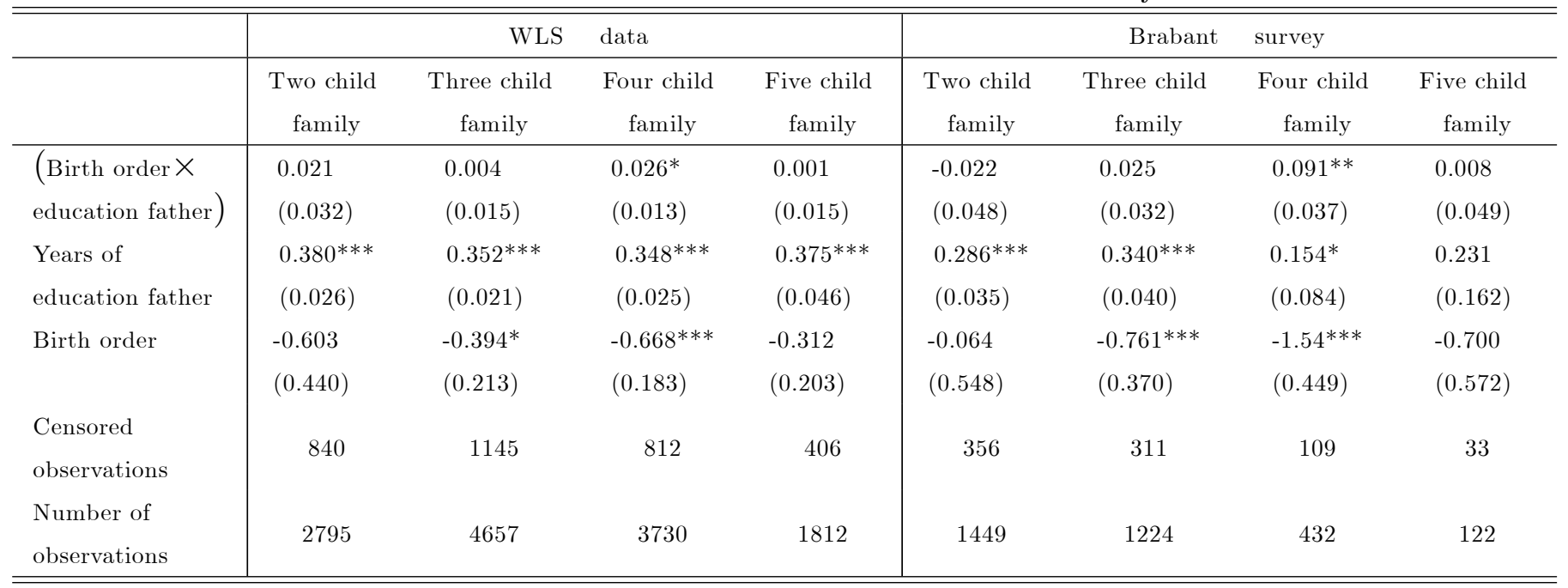

All regressions include control variables for gender and age of the child. Standard errors (in parentheses) allow

for correlation within families. ${ }^{*}$ significant at $10 \%$ level, ${ }^{* *}$ significant at $5 \%$ level, ${ }^{* * *}$ significant at $1 \%$ level. 
Table 8 . The effect of the average time between births on years of education

\begin{tabular}{|c|c|c|c|c|c|c|c|c|}
\hline & \multicolumn{4}{|c|}{ WLS } & \multicolumn{4}{|c|}{ Brabant survey } \\
\hline & $\begin{array}{l}\text { Two child } \\
\text { family }\end{array}$ & $\begin{array}{c}\text { Three child } \\
\text { family }\end{array}$ & $\begin{array}{c}\text { Four child } \\
\text { family }\end{array}$ & $\begin{array}{l}\text { Five child } \\
\text { family }\end{array}$ & $\begin{array}{c}\text { Two child } \\
\text { family }\end{array}$ & $\begin{array}{c}\text { Three child } \\
\text { family }\end{array}$ & $\begin{array}{c}\text { Four child } \\
\text { family }\end{array}$ & $\begin{array}{c}\text { Five child } \\
\text { family }\end{array}$ \\
\hline Averagespace & -0.003 & 0.002 & -0.002 & -0.009 & 0.002 & $-0.015^{*}$ & -0.002 & -0.004 \\
\hline in months & $(0.003)$ & $(0.003)$ & $(0.005)$ & $(0.010)$ & $(0.006)$ & $(0.008)$ & $(0.012)$ & $(0.040)$ \\
\hline Birth order & $-0.300^{* * *}$ & $-0.284^{* * *}$ & $-0.350 * * *$ & $-0.196^{* *}$ & -0.281 & $-0.455^{* * *}$ & $-0.507^{* *}$ & -0.561 \\
\hline & $(0.100)$ & $(0.060)$ & $(0.061)$ & $(0.081)$ & $(0.185)$ & $(0.152)$ & $(0.219)$ & $(0.402)$ \\
\hline \multicolumn{9}{|l|}{$\begin{array}{l}\text { With } \\
\text { interaction }\end{array}$} \\
\hline (Averagespace & 0.002 & 0.002 & $-0.009 * * *$ & 0.002 & -0.007 & -0.008 & -0.016 & 0.003 \\
\hline$\times$ Birth order $)$ & $(0.005)$ & $(0.003)$ & $(0.003)$ & $(0.005)$ & $(0.009)$ & $(0.009)$ & $(0.011)$ & $(0.014)$ \\
\hline Averagespace & -0.004 & 0.0005 & 0.010 & -0.012 & 0.005 & -0.008 & 0.016 & -0.009 \\
\hline in months & $(0.003)$ & $(0.004)$ & $(0.007)$ & $(0.013)$ & $(0.006)$ & $(0.011)$ & $(0.015)$ & $(0.050)$ \\
\hline \multirow[t]{2}{*}{ Birth order } & $-0.363^{* *}$ & $-0.340^{* * *}$ & -0.107 & $-0.233^{*}$ & -0.039 & -0.216 & -0.090 & -0.641 \\
\hline & $(0.162)$ & $(0.102)$ & $(0.099)$ & $(0.131)$ & $(0.327)$ & $(0.290)$ & $(0.311)$ & $(0.395)$ \\
\hline $\begin{array}{l}\text { Censored } \\
\text { observations }\end{array}$ & 662 & 799 & 541 & 229 & 346 & 301 & 105 & 32 \\
\hline $\begin{array}{l}\text { Number of } \\
\text { observations }\end{array}$ & 2490 & 4040 & 3122 & 1436 & 1394 & 1171 & 408 & 117 \\
\hline
\end{tabular}

All regressions include control variables for gender and age of the child, years of education mother and years of education father. Standard errors (in parentheses) allow for correlation within families.*significant at $10 \%$ level, ${ }^{* *}$ significant at $5 \%$ level, ${ }^{* * *}$ significant at $1 \%$ level. 
Table 9: First stage; the effect of the presence of twins on the average space between births, in months

\begin{tabular}{|c|c|c|c|c|c|c|c|}
\hline & \multicolumn{4}{|c|}{ WLS data } & \multicolumn{3}{|c|}{ Brabant survey } \\
\hline & $\begin{array}{l}\text { Two child } \\
\text { family }\end{array}$ & $\begin{array}{c}\text { Three child } \\
\text { family }\end{array}$ & $\begin{array}{l}\text { Four child } \\
\text { family }\end{array}$ & $\begin{array}{l}\text { Five child } \\
\text { family }\end{array}$ & $\begin{array}{l}\text { Two child } \\
\text { family }\end{array}$ & $\begin{array}{c}\text { Three child } \\
\text { family }\end{array}$ & $\begin{array}{l}\text { Four child } \\
\text { family }\end{array}$ \\
\hline \multicolumn{8}{|l|}{ A: Full sample } \\
\hline $\begin{array}{l}\text { Presence of } \\
\text { twins }\end{array}$ & $\begin{array}{c}-35.874^{* * *} \\
(1.194)\end{array}$ & $\begin{array}{c}-15.097^{* * *} \\
(2.296)\end{array}$ & $\begin{array}{c}-7.725^{* * *} \\
(1.746)\end{array}$ & $\begin{array}{c}-6.152^{* * *} \\
(1.681)\end{array}$ & $\begin{array}{c}-34.453^{* * *} \\
(1.208)\end{array}$ & $\begin{array}{c}-15.449^{* * *} \\
(3.551)\end{array}$ & $\begin{array}{l}-4.477^{*} \\
(2.421)\end{array}$ \\
\hline Partial F-statistic & 903.00 & 43.30 & 19.54 & 13.40 & 813.39 & 18.92 & 3.42 \\
\hline Censored observations & 662 & 799 & 541 & 229 & 346 & 301 & 105 \\
\hline Number of observations & 2490 & 4040 & 3122 & 1431 & 1394 & 1171 & 408 \\
\hline \multicolumn{8}{|l|}{$\begin{array}{l}\text { B: Sample excluding } \\
\text { children part of a twin }\end{array}$} \\
\hline $\begin{array}{l}\text { Presence of } \\
\text { twins }\end{array}$ & - & $\begin{array}{c}-15.278^{* * *} \\
(2.330)\end{array}$ & $\begin{array}{c}-7.764^{* * *} \\
(1.845)\end{array}$ & $\begin{array}{l}-6.089^{* * *} \\
(1.767)\end{array}$ & - & $\begin{array}{c}-16.051^{* * *} \\
(3.609)\end{array}$ & $\begin{array}{l}-4.299 * \\
(2.595)\end{array}$ \\
\hline Partial F-statistic & - & 43.03 & 17.72 & 11.90 & - & 19.80 & 2.76 \\
\hline Censored observations & - & 777 & 522 & 218 & - & 293 & 99 \\
\hline Number of observations & - & 3984 & 3051 & 1389 & - & 1144 & 388 \\
\hline
\end{tabular}

All regressions include control variables for gender and age of the child, birthorder, years of education mother and years of education father. Standard errors (in parentheses) allow for correlation within families.

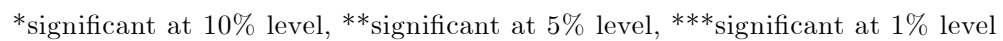

Table 10: The effect of child spacing on years of education; using the presence of twins as instrument

\begin{tabular}{|c|c|c|c|c|c|c|c|}
\hline & \multicolumn{4}{|c|}{ WLS data } & \multicolumn{3}{|c|}{ Brabant survey } \\
\hline & $\begin{array}{l}\text { Two child } \\
\text { family }\end{array}$ & $\begin{array}{c}\text { Three child } \\
\text { family }\end{array}$ & $\begin{array}{c}\text { Four child } \\
\text { family }\end{array}$ & $\begin{array}{l}\text { Five child } \\
\text { family }\end{array}$ & $\begin{array}{l}\text { Two child } \\
\text { family }\end{array}$ & $\begin{array}{c}\text { Three child } \\
\text { family }\end{array}$ & $\begin{array}{c}\text { Four child } \\
\text { family }\end{array}$ \\
\hline \multicolumn{8}{|l|}{ A: Full sample } \\
\hline Averagespace & -0.011 & -0.031 & -0.048 & 0.008 & -0.0026 & 0.0067 & 0.114 \\
\hline in months & $(0.024)$ & $(0.025)$ & $(0.033)$ & $(0.050)$ & $(0.020)$ & $(0.050)$ & $(0.208)$ \\
\hline Censored observations & 662 & 799 & 541 & 229 & 346 & 301 & 105 \\
\hline Number of observations & 2490 & 4040 & 3122 & 1431 & 1394 & 1171 & 408 \\
\hline \multicolumn{8}{|l|}{$\begin{array}{l}\text { B: Sample excluding } \\
\text { children part of a twin }\end{array}$} \\
\hline $\begin{array}{l}\text { Averagespace } \\
\text { in months }\end{array}$ & - & $\begin{array}{c}-0.079^{* * *} \\
(0.030)\end{array}$ & $\begin{array}{l}-0.034 \\
(0.037)\end{array}$ & $\begin{array}{r}0.014 \\
(0.060)\end{array}$ & - & $\begin{array}{l}-0.077 \\
(0.069)\end{array}$ & $\begin{array}{r}0.194 \\
(0.264)\end{array}$ \\
\hline Censored observations & - & 777 & 522 & 218 & - & 293 & 99 \\
\hline Number of observations & - & 3984 & 3051 & 1389 & - & 1144 & 388 \\
\hline
\end{tabular}

All regressions include control variables for gender and age of the child, birthorder, years of education mother and years of education father. Standard errors (in parentheses) allow for correlation within families.

*significant at $10 \%$ level, ${ }^{* *}$ significant at $5 \%$ level, $* * *$ significant at $1 \%$ level 


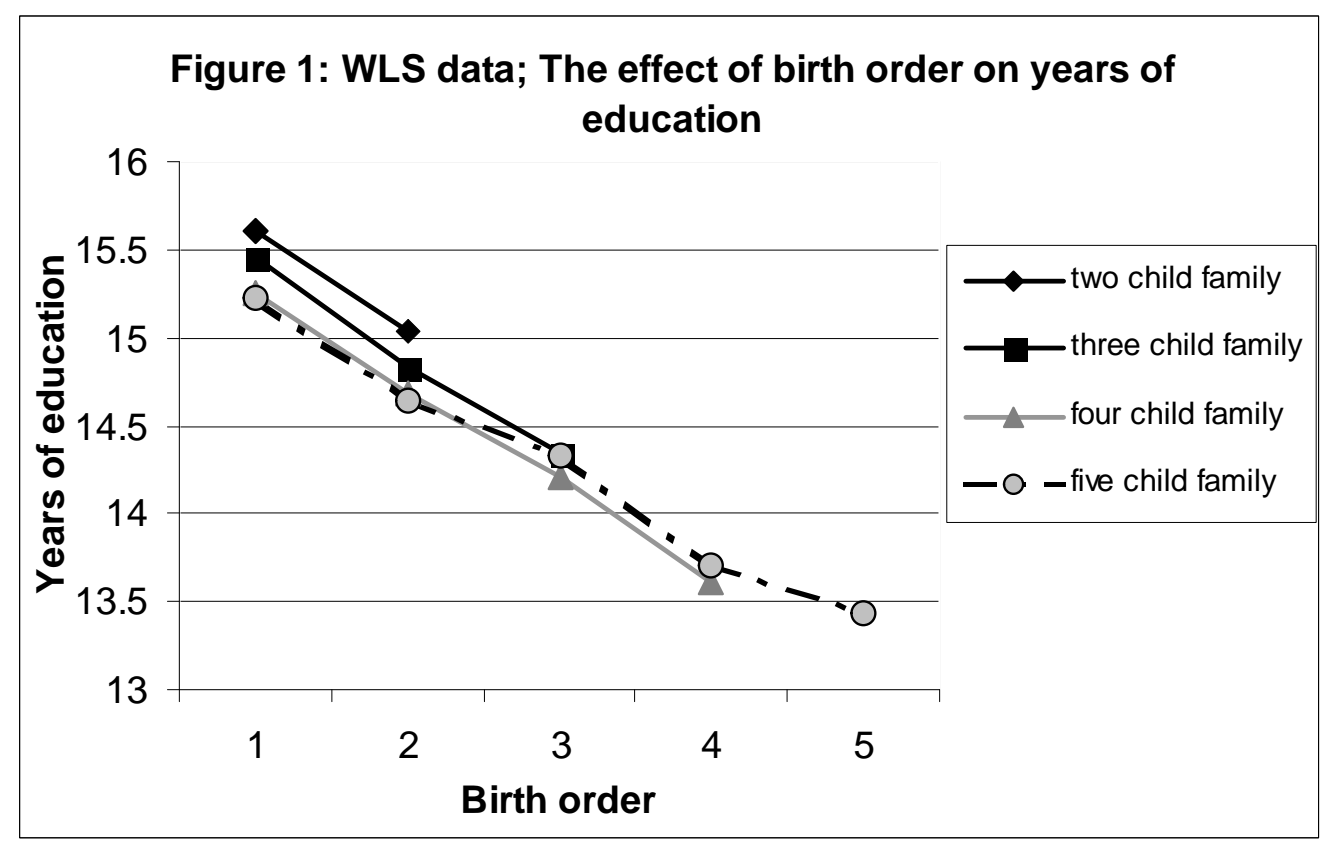

The predicted values are based on the results in table 5 .

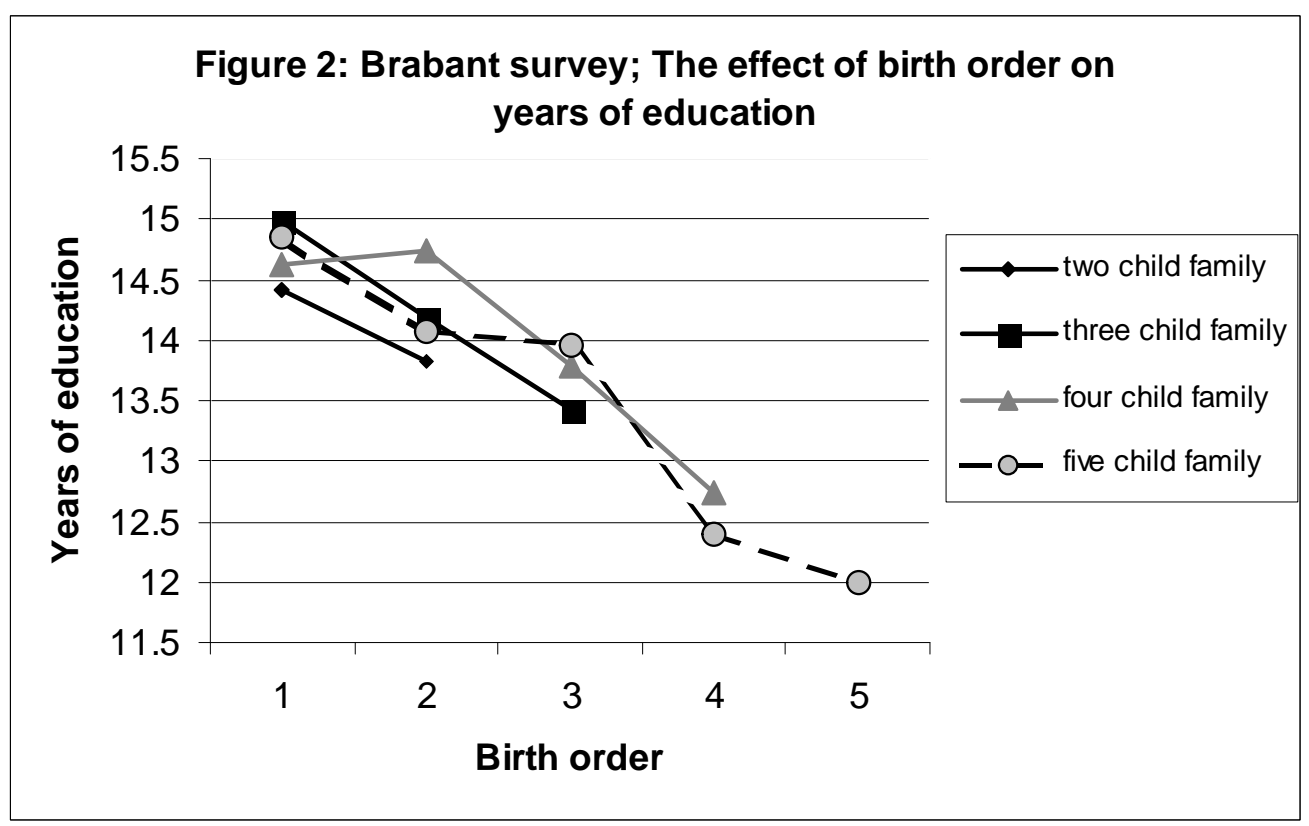

The predicted values are based on the results in table 5 . 
Figure 3: WLS data; The effect of birth order on years of education
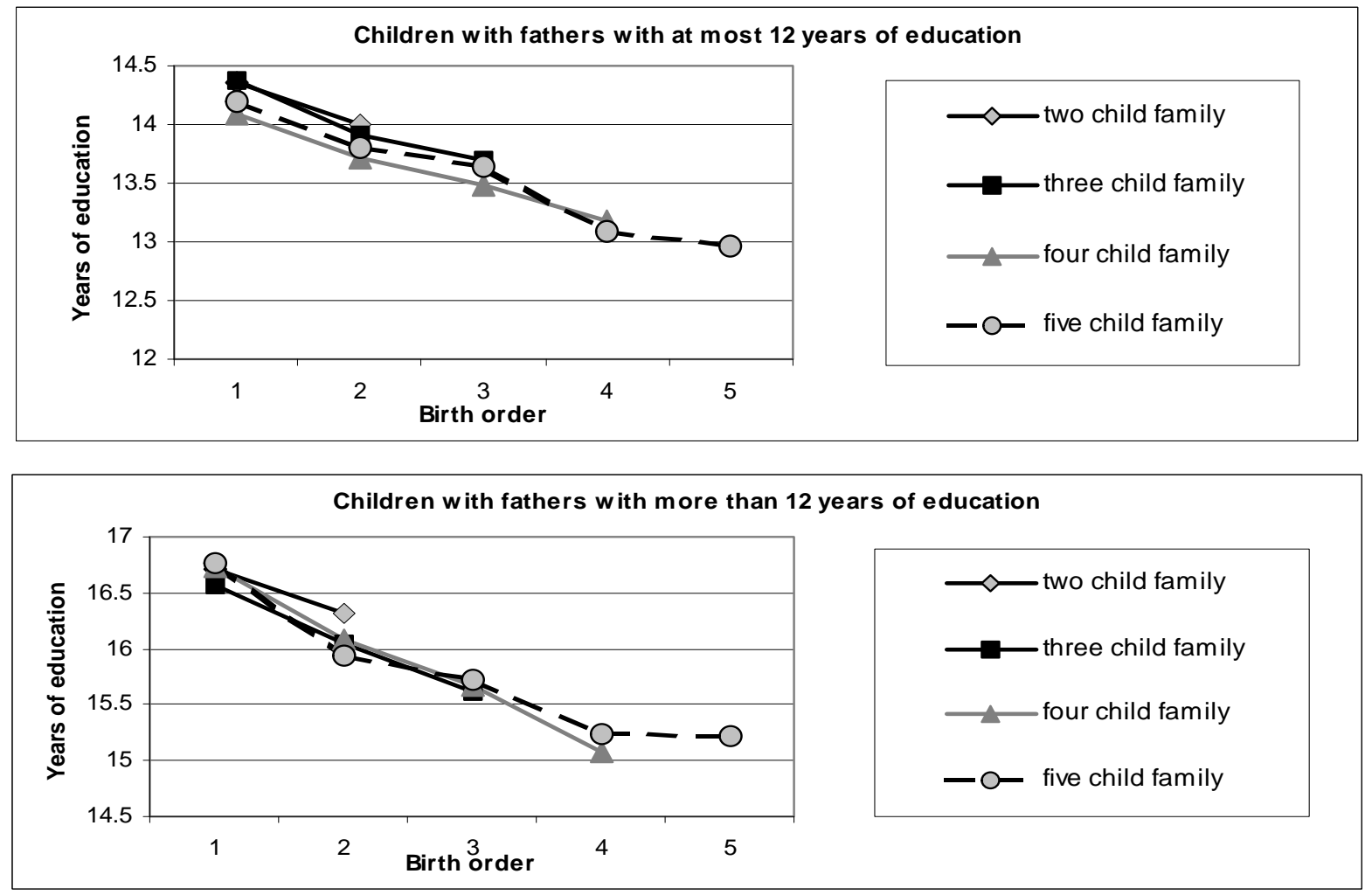

Figure 4: Brabant survey; The effect of birth order on years of education
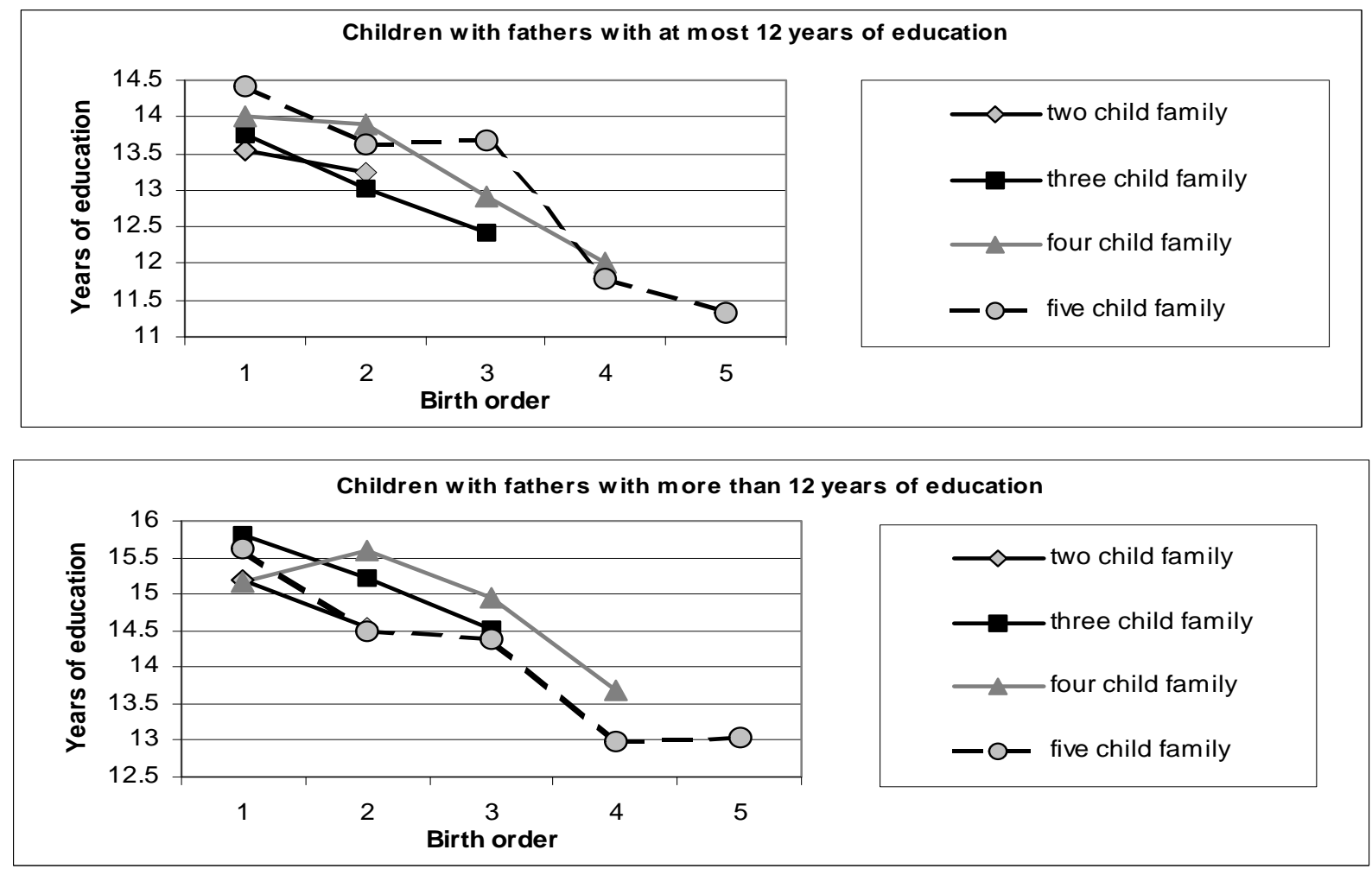


\section{Appendix}

The model which is estimated in subsection 5.2 is the following:

$$
\begin{gathered}
E_{\text {child }, i}^{*}=\alpha_{0}+\alpha_{1} \cdot \text { numberofchild }_{i}+X_{i} \cdot \beta+v_{i} \\
\text { numberofchild }_{i}=\delta_{0}+\delta_{1} \cdot Z_{i}+X_{i} \cdot \psi+\eta_{i}
\end{gathered}
$$

Whereby

$$
\begin{aligned}
& E_{\text {child }}^{*}=E_{\text {child }} \text { if a child is no longer in school }\left(d_{i}=0\right) \\
& E_{\text {child }}^{*} \geq E_{\text {child }} \text { if a child is still in school }\left(d_{i}=1\right)
\end{aligned}
$$

$E_{\text {child }}^{*}$ is the final number of years of education, $E_{\text {child }}$ is the observed number of years of education and $Z_{i}$ is the instrumental variable for the number of children. It is assumed that $v_{i}$, $\eta_{i}$ are multivariate normally distributed:

$$
\left[\begin{array}{l}
v_{i} \\
\eta_{i}
\end{array}\right] \sim N\left(\left[\begin{array}{l}
0 \\
0
\end{array}\right],\left[\begin{array}{cc}
\sigma_{v}^{2} & \Sigma_{21}^{\prime} \\
\Sigma_{21} & \Sigma_{22}
\end{array}\right]\right)
$$

Using the properties of the multivariate normal distribution we have that the distribution of $v_{i}$ conditional on $\eta_{i}$ is equal to

$$
v_{i} \mid \eta_{i} \sim N\left(\Sigma_{22}^{-1} \Sigma_{21} \cdot \eta_{i}, \sigma_{v}^{2}-\Sigma_{21}^{\prime} \Sigma_{22}^{-1} \Sigma_{21}\right)
$$

From this we have that $v_{i}=\pi \cdot \eta_{i}+\varepsilon_{i}$, whereby $\pi=\Sigma_{22}^{-1} \Sigma_{21}$ and $\varepsilon_{i} \sim N\left(0, \sigma_{v}^{2}-\Sigma_{21}^{\prime} \Sigma_{22}^{-1} \Sigma_{21}\right)$. Substituting this result for $v_{i}$ into equation (3) gives

$$
\begin{array}{r}
E_{\text {child }, i}=\alpha_{0}+\alpha_{1} \cdot \text { numberofchild }_{i}+X_{i} \cdot \beta \\
+\pi\left(\text { numberofchild } d_{i}-\delta_{0}-\delta_{1} \cdot Z_{i}-X_{i} \cdot \psi\right)+\varepsilon_{i}
\end{array}
$$

To derive the likelihood function the joint density of $E_{\text {child,i }}$ and numberof child $i$ is rewritten as the product of the conditional and marginal density:

$$
\begin{aligned}
& f\left(E_{\text {child }, i}, \text { numberof child } i \mid X_{i}, Z_{i}\right)= \\
& f\left(E_{\text {child,i}} \mid \text { numberofchild } i, X_{i}, Z_{i}\right) \cdot f\left(\text { numberofchild }_{i} \mid X_{i}, Z_{i}\right)
\end{aligned}
$$

whereby

$$
\begin{aligned}
& \phi\left(E_{\text {child }, i} \mid \text { numberofchild } d_{i}, X_{i}, Z_{i}, \theta\right) \quad \text { if } d_{i}=0
\end{aligned}
$$

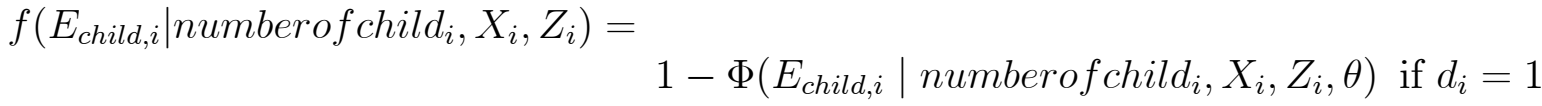

and

$$
f\left(\text { numberofchild }_{i} \mid X_{i}, Z_{i}\right)=\phi\left(\text { numberofchild }_{i} \mid X_{i}, Z_{i}, \theta\right)
$$

The log likelihood for observation $i$ is: 


$$
\ln L_{i}(\theta)=\ln f\left(E_{\text {child, },} \mid \text { numberofchild }{ }_{i}, X_{i}, Z_{i}\right)+\ln f\left(\text { numberof }_{\text {child }} \mid X_{i}, Z_{i}\right)
$$

Using (19), (20) and (21) the final maximum likelihood maximizes

$\ln L(\theta)=\sum_{i=1}^{N}\left[\left(1-d_{i}\right) \cdot \ln \phi\left(E_{\text {child }, i} \mid\right.\right.$ numberofchild $\left._{i}, X_{i}, Z_{i}, \theta\right)+$

$d_{i} \cdot \ln \left\{1-\Phi\left(E_{\text {child,i }} \mid\right.\right.$ numberof child $\left.\left., X_{i}, Z_{i}, \theta\right)\right\}+\ln \phi\left(\right.$ numberof child $\left.\left._{i} \mid X_{i}, Z_{i}, \theta\right)\right]$ 